\title{
CAMA
}

Centre for Applied Macroeconomic Analysis

\section{The Dynamics of Health Care and Growth: A model with physician in dual practice}

\section{CAMA Working Paper 5/2019 January 2019}

Baris Alpaslan

Social Sciences University of Ankara

Centre for Applied Macroeconomic Analysis, ANU

\section{King Yoong Lim}

Nottingham Business School, Nottingham Trent University

\section{Yan Song}

University of Manchester

\begin{abstract}
We present a growth model with micro-foundations of a mixed health care system and physician dual-practice, to analyze for welfare-optimal government financing strategy for a mixed health system in developing countries. Calibrating the model for Indonesia, we find that a government subsidy to private health care is both growth- and welfareenhancing, whereas it is more effective for the government to invest in health infrastructure instead of a public-sector "rewarding" policy in raising government physicians' wage if its goal is to improve physician effort in public practice. Indeed, for the "rewarding" policy, a dynamic trade-off in growth is found, which is not previously documented in the literature. We also find the model to produce two regimes with different welfare-optimal health financing (a "normal" regime and a low public-sector congestion regime). In the former, welfare-optimal health financing strategy appears to be promoting private health subsidy at the expense of public-sector physician wages. In the latter, the opposite is welfare-optimal.
\end{abstract}




\section{Keywords}

Dual Practice, Economic Growth, Health Care Financing, Welfare

\section{JEL Classification}

H51, I11, I15, O41

Address for correspondence:

(E) cama.admin@anu.edu.au

ISSN 2206-0332

The Centre for Applied Macroeconomic Analysis in the Crawford School of Public Policy has been established to build strong links between professional macroeconomists. It provides a forum for quality macroeconomic research and discussion of policy issues between academia, government and the private sector.

The Crawford School of Public Policy is the Australian National University's public policy school, serving and influencing Australia, Asia and the Pacific through advanced policy research, graduate and executive education, and policy impact. 


\title{
The Dynamics of Health Care and Growth: A model with physician in dual practice
}

\author{
Baris Alpaslan*, King Yoong Lim**, and Yan Song*** \\ This version: January 1, 2019
}

\begin{abstract}
We present a growth model with micro-foundations of a mixed health care system and physician dual-practice, to analyze for welfare-optimal government financing strategy for a mixed health system in developing countries. Calibrating the model for Indonesia, we find that a government subsidy to private health care is both growth- and welfare-enhancing, whereas it is more effective for the government to invest in health infrastructure instead of a public-sector "rewarding" policy in raising government physicians' wage if its goal is to improve physician effort in public practice. Indeed, for the "rewarding" policy, a dynamic trade-off in growth is found, which is not previously documented in the literature. We also find the model to produce two regimes with different welfare-optimal health financing (a "normal" regime and a low public-sector congestion regime). In the former, welfare-optimal health financing strategy appears to be promoting private health subsidy at the expense of public-sector physician wages. In the latter, the opposite is welfare-optimal.
\end{abstract}

JEL Classification Numbers: H51, I11, I15, O41

Keywords: Dual Practice, Economic Growth, Health Care Financing, Welfare.

*Social Sciences University of Ankara. Also, Research Associate, Centre for Applied Macroeconomic Analysis (CAMA), Crawford School of Public Policy, ANU; ** Corresponding author, Nottingham Business School, Nottingham Trent University, Email: king.lim@ntu.ac.uk; ***University of Manchester. We would like to thank the helpful comments and feedback from an anonymous reviewer. All views expressed in the article are our own. 


\section{Introduction}

The question on what constitutes the best policy approach in managing and financing a national health system in a developing economy remains a subject of much debate. As summarized in Saksena et al. (2010), for some the expansion of private health services to complement public health provision is desirable as this represents a gain in efficiency and the quality of health care, while for others the private sector is inherently inequitable and could create disincentive for health workers to provide their best efforts in public practice, especially those who engage in dual practice (Iversen, 1997; Berman and Cuizon, 2004). Indeed, physician dual practice can exist in various different forms and is prevalent in numerous health systems of developing countries where the demarcation of private and public health service provision is not clear (McPake et al., 2011; McPake et al., 2014; Hipgrave and Hort, 2014). In many developing economies, especially those with geographically sparse regions, the government often has to channel public funding to support private health facilities, in addition to the wage bill of government doctors. Indeed, the role of government in subsidizing private health service cost in developing economies is highlighted in Lagomarsino et al. (2012), who reviewed health insurance reforms in nine developing countries in Africa and Asia. Similarly, a recent example is the Indonesia's national health system, where true private voluntary health insurance is not well-developed and the existing "private" health financing schemes are mostly public owned, resulting in the government essentially supporting both public and private health care. ${ }^{1}$ In an attempt to achieve universal health coverage by 2019 (Thabrany, 2008), Indonesia launched its current BPJS Kesehatan system in 2014 and effectively doubled down on the government's role in financing a mixed health system, since BPJS administers the national health insurance, Jaminan Kesehatan Nasional. However, ever since 2014, the system has been facing a deficit, in that the system incurs significantly more expenses than the revenue it receives, yet without a marked improvement in the aggregate health outcome (Fossati, 2017; Pisani et al., 2017).

\footnotetext{
${ }^{1}$ See Rokx et al. (2009) for a description of the major health financing programs in Indonesia prior to the introduction of the current BPJS Kesehatan system since 2014. In short, despite being structured as private institutions that also sell private commercial policies, P.T. Askes and P.T. Jamsostek were administered by the Ministry of Health and were therefore akin to private health service provider being subsidized by the government. While both have been succeeded by BPJS Kesehatan and BPJS Ketanagakerjaan under the new system, similar structures of government insurance companies are retained.
} 
The case of Indonesia raises important knowledge gaps in the present literature on health financing, which this study attempts to address. First, despite the large microeconomic literature focusing on examining the implications of physician dual practice and the welfare effects of different regulations, to our knowledge, the link to the overall financing of a national health system is not explored. Second, while there are existing theoretical growth models focusing on examining the links between health expenditure and economic growth, the effects of physician dual practice on consumers' choice in a mixed health system have never been examined. Third, while there exists a rich variety of case studies and country-level reports, there remains a vacuum in terms of generalizable theoretical study that seeks to identify the overall welfare implications associated with the dynamic trade-off of public and private health financing made by the government. We address these by developing an endogenous growth model with micro-foundations of a mixed health care system and physician dual-practice, to analyze for potential (or lack thereof) welfare-optimal government financing strategy for a mixed health system in developing countries. To preview, based on a stylized model parameterization for Indonesia, we find that a government subsidy to private health care is both growth- and welfare-enhancing, whereas it is more effective for the government to invest in health infrastructure instead of a public-sector "rewarding" policy in raising government physicians' wage if its goal is to improve physician effort in public practice. Indeed, for the "rewarding" policy, a dynamic trade-off in growth (between instantaneous and steady-state effects) is found, which is not previously documented in the existing literature. We also find the model solutions to produce two different regimes (a "normal" regime and a low publicsector congestion regime). In the normal regime, welfare-optimal health financing strategy appears to be promoting private health service, even if it is at the expense of public-sector physician wages. In contrast, in a low-congestion, high capacity regime, a welfare-optimal strategy is to do the opposite of increasing government physician wage at the expense of private health subsidy. These findings suggest that the question of an optimal financing of a mixed health system in developing countries does not have a straightforward answer, which perhaps explains the current underperformance of Indonesia's BPJS Kesehatan system.

The rest of the article is structured as follows. Section 2 provides a brief review on the relevant literature. Section 3 presents the model, and following the definition of the relevant 
equilibrium concepts, proceeds to solve for the dynamic system characterizing the model solutions. In Section 4, the model is calibrated for Indonesia. After that, we analyze the model properties by implementing a series of policy experiments in Section 5 . Section 6 draws on policy implications from the experiments to conclude the article.

\section{Literature Review}

In the microeconomic literature on physician dual practice, it is well established that dual practice is prevalent in numerous health systems of developed and developing countries. For instance, in the UK approximately two-thirds of NHS (National Health Service) consultants have significant private work (Humphrey and Russell, 2004). According to the newest 2016 Indonesian Family Life Survey, at least 50 percent of the public community physicians reported to have a private practice. Similarly, Gruen et al. (2002) believe that more than 80 percent of the government physicians in Bangladesh engage in private practice, while Russo et al. (2013) show that 55 percent of physicians surveyed in three African cities engaged in dual practice. The literature of dual practice in a mixed health market is limited but growing. Thorough reviews of existing literature of physician dual practice have been studied by Eggleston and Bir (2006), García-Prado and González (2007), Socha and Bech (2011), and Moghri et al. (2017). Some studies, such as Ferrinho et al. (2004), Humphrey and Russell (2004), and Askildsen and Holmås (2013) explored the motivation of physician for having dual practice. The consensus arrived is that, public physicians engage in dual practice mainly due to the two reasons of financial incentive and strategic influence. These imply that, while low public pay does create the incentive for private practice (Ferrinho et al. 1998), physicians also appreciate the greater freedom and efficiency in the private sector. However, there are other studies that suggest that, allowing physician dual practice is costly and has negative impacts on the quality of public health care. González $(2004,2005)$ argue that dual-practice physician may over-provide medical services in public in order to increase his prestige, and divert low-cost patients to his private practice in order to achieve his financial aim. Brekke and Sørgard (2007) develop a theoretical model to argue that allowing physician dual practice will induce physicians to provide less supply or attention in the public sector, which in 
turn leads to lower overall health provision. However, they did suggest that allowing dual practice in a mixed health care market may be socially desirable. This view is shared by Biglaiser and Ma (2007), who develop another model that suggests allowing dual practice always enhances aggregate patients' welfare, even though dual-practice physicians may refer patients to their private practices. Indeed, González and Macho-Stadler (2013) fnd that an outright ban on dual practice is seldom optimal, though the various scenarios they have examined suggest that different policy interventions may be warranted for different health systems.

As mentioned, while the microeconomic literature has reviewed the welfare effects of various regulations affecting dual practice, but an explicit link to the relatively macroeconomic issue of government financing of the national health system is not well explored. By implication of this missing link that bridges the microeconomic and macroeconomic issues, the effect of dual practice on the average health status of the population and consequently, productivity and economic growth is also not well understood. This is despite over 200 years of empirical evidence on health-led growth discussed and documented in Madsen (2018). In the growth literature, while the benefits of government's health expenditure are well-documented, both in theoretical studies (Chakraborty, 2004; Agénor, 2008, 2015) and empirical studies (Heshmati, 2001; Rivera and Currais, 2004; Wang, 2011), to our knowledge, the interaction between public and private expenditure on health has only been modeled in a simplistic manner. Specifically, in studies such as Bhattacharya and Qiao (2007), private health expenditure is modeled as generational investment for old age, while public expenditure as largely exogenous. Similarly, in studies such as Chakraborty and Das (2005), Osang and Sakar (2008) and Kunze (2014), the positive non-linearity between life expectancy and economic growth is explained in the context of inter-generational human capital investment. In essence, most of these studies, including peripheral models focusing on health-gender equality (Agénor et al., 2014) and health-environment nexus (Mariani et al., 2010), model health mainly in the context of children, with the subsequent adult health status being a result of persistence. The feature of health-service quality that determines patients' choice of health care and therefore directly on adult health status has therefore never been considered. Addressing this missing link between microeconomic and macroeconomic of health literature is 
therefore our primary motivation.

\section{The Model}

Consider an economy with discrete time $t=0,1, \ldots, \infty$. Population is constant and normalized to $\bar{N}=1$, and consists of two-period lived individuals (adulthood and old age) with largely identical preferences, save for having different valuation of the quality of health services. Due to this difference, individuals' willingness-to-pay for health care are mapped along a continuous distribution, indexed by $\xi \in(0,1)$. Individuals use either public health care (free of charge) or private health services. The consumption for health care arises due to a homogenous illness assumed to occur at the beginning of adulthood, which affects the health status of individuals. There is a survival probability of $\pi_{t}$ in which individuals survive to old age. Each individual is risk neutral and endowed with one unit of time in each period of life. In old age, time is allocated entirely to leisure. Population is constant at $\bar{N}$. Savings are held only in the form of physical capital. Individuals have no other endowments, except for initial stocks of health $\left(h_{0}\right)$ and physical capital $\left(K_{0}^{P}\right)$ at time $t=0$.

In addition to private individuals, there is a representative physician who allocates his one unit of effort among leisure, public practice, and private practice. ${ }^{2}$ The latter is supplied to a price-taking private hospital. Given that the physician gets to set his private-practice wage, he will always prefer private practice. The effort in private practice is therefore demanddetermined. The physician's wage in the public health care system is paid by a balancedbudget government, who also spends on health infrastructure and subsidizes private health care cost incurred by the households. Lastly, there is a continuum of identical price-taking firms producing non-storable final goods used either for consumption or investment. There is imperfect information for firms in that they observe only the average labor efficiency level and therefore pays a common efficiency wage to all labor.

\footnotetext{
${ }^{2}$ Alternatively, a different model with many physicians can be written that allows for the proportion of physicians to be determined endogenously, at the cost of greater model complexity. This can be done by introducing a training cost component similar to the skilled labor specification in Agénor and Lim (2018). However, given that the size of physicians is usually very small (for instance, in 2010, the number of physicians per 1000 people in Indonesia is only 0.14 ), this is not pursued in this study.
} 


\subsection{Preferences and Health Status}

There is a continuum of individuals, mapped by their different observable willingness-topay, $\xi \in(0,1)$, receives net wage income (paid by firms according to the average labor efficiency level in the economy) by supplying labor. The wage income is either saved, spent in consuming final goods, or for those who opt so, in private health care. Health services in the economy are provided either by public hospital (free of charge) or private hospital (incurring a health care cost, $h c_{t}$ ). $\xi$ follows a continuous distribution with density function $f(\xi)$ and cumulative distribution function $F(\xi)$. For tractability, $\xi$ is assumed to be uniformly distributed on its support.

The expected lifetime utility at the beginning of period $t$ of an individual $j=P H, G H$ is given by

$$
V_{t}^{j}=\ln \left(c_{t}^{j}\right)^{\kappa}\left(h_{t}^{j}\right)^{1-\kappa}+\Lambda \pi_{t} \mathbb{E}_{t}\left[\ln \left(c_{t+1}^{j}\right)^{\kappa}\left(h_{t+1}^{j}\right)^{1-\kappa}\right]
$$

where $c_{t}^{j}\left(c_{t+1}^{j}\right)$ denotes consumption of final good in adulthood (old age) for individual $j, h_{t}^{j}$ $\left(h_{t+1}^{j}\right)$ is the health status of an individual $j$ in adulthood (old age), $\pi_{t} \in[0,1]$ is the survival probability common to all individuals regardless of whether they use private $(j=P H)$ or public health care $(j=G H), \kappa$ measures the relative contribution of ordinary consumption to utility, $\Lambda<1$ is the discount factor, $\mathbb{E}_{t}$ the expectation operator conditional on information at time $t$. The specification assumes a realistic non-independence of ordinary consumption and health status, which is consistent with studies such as Agénor (2008). For simplicity, we assume individuals do not derive disutility from working.

In typical fashion, the period-specific budget constraints are given by

$$
\begin{gathered}
c_{t}^{j}+s_{t}^{j}=\left\{\begin{array}{ll}
(1-\tau) a_{t}^{A} w_{t}-h c_{t}, & \text { if } j=P H \\
(1-\tau) a_{t}^{A} w_{t} & \text { if } j=G H
\end{array},\right. \\
\pi_{t} c_{t+1 \mid t}^{j}=\left(1+r_{t+1}\right) s_{t}^{j}, \quad j=P H, G H .
\end{gathered}
$$

where $a_{t}^{A} w_{t}$ is the efficiency wage $\left(a_{t}^{A}\right.$ the average labor efficiency in the economy, $w_{t}$ the wage rate), $\tau \in(0,1)$ the tax rate, $s_{t}$ saving, and $r_{t+1}$ the rental rate of private capital in period $t+1$. Equation (3) indicates that individuals consume in old age $(t+1)$ with a 
probability $\pi_{t} \cdot^{3}$

Solving for the individual's utility maximization problem with respect to intertemporal consumption yields the Euler equation,

$$
\frac{\mathbb{E}_{t} c_{t+1}^{j}}{c_{t}^{j}}=\Lambda\left(1+r_{t+1}\right) .
$$

Due to the one-off nature of the illness and the heterogeneity in the willingness-to-pay, individuals' choice of health services are solely determined by their relative position along the $\xi$ distribution. As such, a one-to-one mapping in a uniform distribution with support $(0,1)$ means we can also express $\xi_{t}$ as the share of individuals who use free public health services while $1-\xi_{t}$ pays for private health care. The actual health status of an individual $j=P H, G H$ is therefore given by

$$
h_{t}^{j}=\left\{\begin{array}{ll}
\theta h_{0}\left(e_{t}^{P H}\right)^{\nu_{H}}\left(H_{t}^{G}\right)^{\nu_{C}}, & \text { if } j=P H \\
\frac{\theta h_{0}}{\left(\xi_{t} N\right)^{\chi}}\left(e_{t}^{G H}\right)^{\nu_{H}}\left(H_{t}^{G}\right)^{\nu_{C}} & \text { if } j=G H
\end{array},\right.
$$

where $\nu_{H}, \nu_{C} \geq 0, \theta \in(0,1)$ measures the effect of the illness, $h_{0}^{j}$ a constant initial health, $e_{t}^{P H}$ and $e_{t}^{G H}$ the efforts level allocated by the physician in private and public practice respectively, and $H_{t}^{G}$ the broad health infrastructure made available by the government for everyone in the economy. Unlike March and Schroyen (2005), we do not explicitly introduce a waiting time for public health service. Instead, the quality of public health service (and its impact on health status) is subject to congestion/capacity issue associated with the overall size of public patients, where the more public patients use free government health care, the quality each patient receives will be lower, therefore affecting health status. ${ }^{4}$ However, given that $\xi_{t} \bar{N} \in[0,1]$, the smaller the $\chi$ is, the larger the congestion, $\left(\xi_{t} \bar{N}\right)^{\chi}$, is.

For old age, given the presence of the non-zero mortality rate, we follow Agénor et al.

\footnotetext{
${ }^{3}$ Alternatively, it could be assumed that the saving left by agents who do not survive to old age is confiscated by the government, which transfers them in lump-sum fashion to surviving members of the same cohort. The effective rate of return to saving would thus be $\left(1+r_{t+1}\right) / \pi_{t}$, which would yield an equation similar to (3).

${ }^{4}$ A classic example of this is the National Health Service (NHS) system in England, where patients often suffer from long waits and poor service quality in the government hospitals, which is not the case for the private hospitals. These can be referred to the various publications of Care Quality Commission concerning results from the National Patient Survey Programme.
} 
(2014) and Agénor (2015) to specify

$$
h_{t+1}^{j}=\pi_{t} h_{t}^{j}, \quad j=P H, G H .
$$

Likewise, for simplicity, labor efficiency is specified as having a one-to-one relationship to health status, in that

$$
\begin{gathered}
a_{t}^{A}=h_{t}^{A}, \quad \text { where } \\
h_{t}^{A}=\left(1-\xi_{t}\right) h_{t}^{P H}+\xi_{t} h_{t}^{G H},
\end{gathered}
$$

or equivalently, given (5),

$$
h_{t}^{A}=\theta h_{0}\left(H_{t}^{G}\right)^{\nu_{C}}\left[\left(e_{t}^{P H}\right)^{\nu_{H}}\left(1-\xi_{t}\right)+\left(e_{t}^{G H}\right)^{\nu_{H}} \frac{\left(\xi_{t}\right)^{1-\chi}}{(\bar{N})^{\chi}}\right]
$$

An individual finds it optimal to pay for private health care if his/her expected lifetime utility exceeds the expected utility of using only public health care, $\mathbb{E}_{t}\left(V_{t}^{P H}\right) \geq \mathbb{E}_{t}\left(V_{t}^{G H}\right)$, or equivalently,

$$
\begin{aligned}
& \ln \left(c_{t}^{P H}\right)^{\kappa}\left(h_{t}^{P H}\right)^{1-\kappa}+\Lambda \pi_{t} \mathbb{E}_{t}\left[\ln \left(c_{t+1}^{P H}\right)^{\kappa}\left(h_{t+1}^{P H}\right)^{1-\kappa}\right] \\
\geq & \ln \left(c_{t}^{G H}\right)^{\kappa}\left(h_{t}^{G H}\right)^{1-\kappa}+\Lambda \pi_{t} \mathbb{E}_{t}\left[\ln \left(c_{t+1}^{G H}\right)^{\kappa}\left(h_{t+1}^{G H}\right)^{1-\kappa}\right] .
\end{aligned}
$$

There exists a threshold value of the willingness-to-pay, $\xi_{t}^{C}$, above which all individuals with higher value would opt to pay for private health care. In specifying (10), we assume that an individual knows if his/her willingness-to-pay is above or below the threshold $\xi^{C}$ and can therefore decide whether to pay for private health care or not at the beginning of adulthood. ${ }^{5}$ For analytical tractability, the private (interpretable as out-of-pocket) health care cost is specified to be proportional to the gross efficiency wage income:

$$
h c_{t}=\mu_{t} a_{t}^{A} w_{t}
$$

where $\mu_{t} \in R, \mu_{t}=\left(\mu_{0}-s_{t}^{H}\right), \mu_{0} \in(0,1)$, and $s_{t}^{H}$ a private (per individual) health care

\footnotetext{
${ }^{5}$ Equation (10) is assumed to hold as a strict inequality for the individual with the highest $\xi$, that is, $\xi=1$, otherwise nobody would choose to pay for private healthcare.
} 
subsidy provided by the government in period $t$. Conceptually, $\mu_{t}$ can either be positive or negative. If $\mu_{t}<0$, it means the private households is receiving a private health care subsidy amount, $s_{t}^{H}$, that exceeds the base cost involved in private health care, $\mu_{0}$.

As shown in the Appendix, setting (10) as equality, we can derive a threshold value $\xi_{t}^{c}$. Let $\xi_{t}^{C}$ denotes the share of individuals using public health services and $1-\xi_{t}^{C}$ the share using private, and given that uniform distribution means $\xi_{t}^{C}=\bar{N} \xi_{0}^{C} \int_{0}^{\xi_{t}^{c}} f(\xi) d \xi=\xi_{0}^{C} \xi_{t}^{c} \bar{N}$ for some multiplicative constant $\xi_{0}^{C} \geq 0$, we have

$$
\xi_{t}^{C}=\xi_{0}^{C} \frac{\Omega_{t}}{\bar{N}}\left(\frac{e_{t}^{G H}}{e_{t}^{P H}}\right)^{\frac{\nu_{H}}{\chi}}, \text { where } \Omega_{t}=\left(\frac{1-\tau-\mu_{t}}{1-\tau}\right)^{-\frac{\kappa}{\chi}}
$$

\subsection{Private health care}

There is a price-taking private hospital that receives its revenue in the form of the total private health care cost, $h c_{t}$, paid by the $1-\xi_{t}^{C}$ individuals. Taking this revenue, individuals' health care choice $\left(\xi_{t}^{C}\right)$, physician's efforts in public practice $\left(e_{t}^{G H}\right)$, and the private-practice wage rate, $w_{t}^{P H}$ (determined monopolistic competitively by the physician) as given, the private hospital chooses the amount of physician efforts, $e_{t}^{P H}$, to maximizes profits,

$$
\max _{e_{t}^{P H}} \Pi_{t}^{P H}=\left(1-\xi_{t}^{C}\right) \bar{N} \mu_{t} a_{t}^{A} w_{t}-w_{t}^{P H} e_{t}^{P H}
$$

Given (7) and (9), and knowing that $\bar{N}=1$, we derive the demand function of $e_{t}^{P H}$,

$$
e_{t}^{P H}=\left(\mu_{t} \nu_{H} \theta h_{0}\right)^{\frac{1}{1-\nu_{H}}}\left(\frac{w_{t}}{w_{t}^{P H}}\right)^{\frac{1}{1-\nu_{H}}}\left(H_{t}^{G}\right)^{\frac{\nu_{C}}{1-\nu_{H}}}\left(1-\xi_{t}^{C}\right)^{\frac{2}{1-\nu_{H}}}
$$

Even though there is only a single representative physician in the economy, the physician in dual practice $\left(e_{t}^{P H}>0\right)$ will always prefer to meet the demand from private hospital, given that he/she has control of the private-practice wage rate. Given the perceived demand function, which determines the marginal revenue, the representative physician therefore behaves as if he/she is in a monopolistically competitive market by setting his/her "price", $P_{t}^{P H}$, to maximize his/her payoff in the private sector. Given that the price in the perceived demand function is given in the price of $P_{t}^{P H}=w_{t}^{P H} / w_{t}$, the physician maximizes 
$\Pi_{t}^{I}=\left(P_{t}^{P H}-1\right) e_{t}^{P H}$. Using (13), we derive the optimal private-practice "price" to be a constant mark-up of:

$$
P_{t}^{P H}=\frac{w_{t}^{P H}}{w_{t}}=\frac{1}{\nu_{H}}
$$

\subsection{Public health care}

The effort level supplied by the physician for public practice, $e_{t}^{G H}$, can be determined using a simple specification developed in Agénor and Aizenman (1999). Specifically, the representative physician has a total of one unit of effort, which is to be spent among leisure, public practice, and private practice. In each period $t$, the physician evaluates a period utility function that depends on the wage and effort in both practices, $U^{D}\left[w_{t}^{P H}, w_{t}^{G H}, e_{t}^{P H}, e_{t}^{G H}\right]$. Without losing any generality, the utility function is specified as

$$
U^{D}\left[w_{t}^{P H}, w_{t}^{G H}, e_{t}^{P H}, e_{t}^{G H}\right]=\ln \left\{\left[e_{t}^{G H} w_{t}^{G H}+e_{t}^{P H} w_{t}^{P H}\right]^{\delta_{R}}\left(1-e_{t}^{P H}-e_{t}^{G H}\right)^{1-\delta_{R}}\right\},
$$

where $\delta_{R} \in(0,1)$.

The optimal level of $e_{t}^{G H}$ is derived by evaluating the physician's participation condition in dual practice. Specifically, for the physician to involve in dual practice, the utility derived from dual practice has to be at least as good as the utility derived from solely practicing in the public health care system:

$$
\begin{aligned}
& \ln \left\{\left[e_{t}^{G H} w_{t}^{G H}+e_{t}^{P H} w_{t}^{P H}\right]^{\delta_{R}}\left(1-e_{t}^{P H}-e_{t}^{G H}\right)^{1-\delta_{R}}\right\} \\
\geq & \ln \left[\left(e_{t}^{G H} w_{t}^{G H}\right)^{\delta_{R}}\left(1-e_{t}^{G H}\right)^{1-\delta_{R}}\right] .
\end{aligned}
$$

In the margin, the physician is indifferent between dual practice and solely practice in the public sector. Setting (16) as equality, we can solve for an expression of the effort level supplied for public health services:

$$
e_{t}^{G H}=\frac{\left(1-e_{t}^{P H}\right)\left(1+\frac{e_{t}^{P H} w_{t}^{P H}}{e_{t}^{G H} w_{t}^{G H}}\right)^{\psi}-1}{\left(1+\frac{e_{t}^{P H} w_{t}^{P H}}{e_{t}^{G H} w_{t}^{G H}}\right)^{\psi}-1}, \text { where } \psi=\delta_{R} /\left(1-\delta_{R}\right)
$$


As such, instead of specifying dual practice as having a negative effect on public performance, as in one of the scenarios examined in González and Macho-Stadler (2013), public effort, $e_{t}^{G H}$, in this framework is a direct outcome from physician's optimizing behavior. In each period $t$, the total income of physician, $e_{t}^{P H} w_{t}^{P H}+e_{t}^{G H} w_{t}^{G H}$, is subject to the same tax rate, $\tau$. For simplicity, the physician is assumed to spend all the after-tax income and does not save.

\subsection{Firms}

There is a continuum of identical firms, indexed by $i \in(0,1)$, producing non-storable final goods used either for consumption or investment. Production requires the use of effective labor and private capital rented from households. Assuming a Cobb-Douglas technology, the production function of firm $i$ takes the form,

$$
Y_{t}^{i}=A_{0}\left[\frac{K_{t}^{P}}{\left(K_{t}^{P, i}\right)^{\varsigma}}\right]^{\omega}\left(a_{t}^{A} N_{t}^{i}\right)^{\beta}\left(K_{t}^{P, i}\right)^{1-\beta}
$$

where $A_{0} \geq 0, a_{t}^{A}$ denotes the average, economy-wide labor efficiency (which is the same for all firms), $K_{t}^{P, i}$ the firm-specific stock of capital, $K_{t}^{P}=\int_{0}^{1} K_{t}^{P, i} d i$ the aggregate private capital stock, $N_{t}^{i}$ the number of adult workers employed by firm $i, \bar{N}$ the total number of adults, $\varsigma, \omega \geq 0$, and $\beta \in(0,1)$. While production exhibits constant returns to scale in firm-specific inputs, similar to Agénor and Yilmaz (2013) and Lim (2018), production also benefits from an Arrow-Romer type of learning externality associated with the economy-wide aggregate private capital stock, which is subject to a congestion effect of $\varsigma$.

The inputs' markets are competitive. Each firm's objective is to maximize profits, $\Pi_{t}^{i}$, with respect to labor services and private capital, taking $a_{t}^{A}$ as given:

$$
\max _{N_{t}^{i}, K_{t}^{P, i}} \Pi_{t}^{i}=Y_{t}^{i}-r_{t} K_{t}^{P, i}-w_{t} a_{t}^{A} N_{t}^{i},
$$

which yields the first-order conditions of

$$
w_{t}=\beta Y_{t}^{i} /\left(a_{t}^{A} N_{t}^{i}\right), \quad r_{t}=(1-\beta) Y_{t}^{i} / K_{t}^{P, i} .
$$


Since all firms are identical, in a symmetric equilibrium, and given that $a_{t}^{A}=h_{t}^{A}$, these conditions become

$$
w_{t}=\beta Y_{t} /\left(h_{t}^{A} \bar{N}\right), \quad r_{t}=(1-\beta) Y_{t} / K_{t}^{P} .
$$

\subsection{Government}

The government taxes effective wages of both the adult individuals and the representative physician at a constant rate $\tau$. It spends a total of $G_{t}^{H}$ on medical research and broad infrastructure, $G_{t}^{G}$ on physician's wage in public practice, $G_{t}^{S}$ on a private health care subsidy, and $G_{t}^{U}$ on other (unproductive) items. It cannot issue bonds and must therefore run a balanced budget in any period $t$, where

$$
G_{t}^{H}+G_{t}^{G}+G_{t}^{S}+G_{t}^{U}=\tau \bar{N} a_{t}^{A} w_{t}+\tau\left(e_{t}^{P H} w_{t}^{P H}+e_{t}^{G H} w_{t}^{G H}\right)
$$

Shares of spending are constant fractions of revenues:

$$
G_{t}^{h}=v_{h}\left[\tau \bar{N} a_{t}^{A} w_{t}+\tau\left(e_{t}^{P H} w_{t}^{P H}+e_{t}^{G H} w_{t}^{G H}\right)\right], \quad h=H, G, S, U
$$

where $v_{h} \in(0,1)$, and $\sum v_{h}=1$. This specification is consistent with studies such as Chakraborty (2004) and Agénor (2015).

From (11), we know that the total bill of private health care subsidy adds up to $G_{t}^{S}=$ $s_{t}^{H} a_{t}^{A} w_{t} \bar{N}\left(1-\xi_{t}^{C}\right)$, which when equating to (22), means the per-individual health care subsidy provided by the government is:

$$
s_{t}^{H}=\frac{v_{S} \tau}{\left(1-\xi_{t}^{C}\right)}\left[\frac{e_{t}^{P H} w_{t}^{P H}+e_{t}^{G H} w_{t}^{G H}}{a_{t}^{A} w_{t} \bar{N}}+1\right] .
$$

Also, given that the total wage bill for public practice is given by $G_{t}^{G}=e_{t}^{G H} w_{t}^{G H}$, we have

$$
e_{t}^{G H} w_{t}^{G H}=\frac{\tau v_{G}}{1-\tau v_{G}}\left[\bar{N} a_{t}^{A} w_{t}+e_{t}^{P H} w_{t}^{P H}\right]
$$

Lastly, to account for both the learning effect from the improving aggregate labor efficiency level in the economy $\left(a_{t}^{A} \bar{N}\right)$, and the wastage due to poor management of the na- 
tional health system commonly observed in developing economies, the production of health infrastructure, $H_{t}^{G}$, is modeled as

$$
H_{t}^{G}=H_{0}^{G}\left[\frac{a_{t}^{A} \bar{N}}{\left(K_{t}^{P, i}\right)^{\varsigma}}\right]^{\eta}\left(\varphi G_{t}^{H}\right)^{\epsilon}
$$

where for consistency, the learning externality $\eta \geq 0$ is specified to be subject to the same congestion factor as the private sector production, and $\varphi, \epsilon \in(0,1)$ capture the spending efficiency and decreasing-return-to-scale properties.

\subsection{Equilibrium and Endogenous Growth}

First, we assume that the representative physician spends all the net after-tax income he/she earns in each period $t$. The asset market-clearing condition therefore only requires the private capital stock in period $t+1$ to be equal to the aggregate savings made by adults in period t. Assuming full depreciation (a reasonable assumption for a long-range model in which individuals live for two periods), we have

$$
K_{t+1}^{P}=\bar{N} s_{t}=\bar{N}\left[\left(1-\xi_{t}^{C}\right) s_{t}^{P H}+\xi_{t}^{C} s_{t}^{G H}\right]
$$

With the saving-investment balance in equilibrium, it is trivial to show that the other markets clear. The following definitions may then be proposed:

Definition 1. A competitive equilibrium for this economy is a sequence of consumption and savings by individuals $\left\{c_{t}, c_{t+1}, s_{t}\right\}_{t=0}^{\infty}$, efforts by the general physician $\left\{e_{t}^{P H}, e_{t}^{G H}\right\}_{t=0}^{\infty}$, private capital stock $\left\{K_{t+1}^{P}\right\}_{t=0}^{\infty}$, prices $\left\{w_{t}, w_{t}^{G H}, w_{t}^{P H}, r_{t+1}\right\}_{t=0}^{\infty}$, health status $\left\{h_{t}^{G H}, h_{t}^{P H}, h_{t}^{A}, h_{t+1}^{A}\right\}_{t=0}^{\infty}$, private health care subsidy $\left\{s_{t}^{H}\right\}_{t=0}^{\infty}$, constant policy parameters $\tau, v_{H}, v_{G}, v_{S}, v_{U}$, such that, given the initial stocks $K_{0}^{P}, h_{0}, H_{0}^{G}>0$, individuals maximize utility, representative physician maximizes payoff, firms maximize profits, the product and asset markets clear, and the government budget is balanced.

Definition 2. A balanced growth equilibrium (BGE) is a competitive equilibrium in which (i) $c_{t}, c_{t+1}, Y_{t}$, and $K_{t}^{P}$ all grow at the constant rate $\gamma$; (ii) all health status $\left(h_{t}^{G H}, h_{t}^{P H}\right.$, $h_{t}^{A}$ ) are constant; (iii) by implications of (i)-(ii), the wage rates $\left(w_{t}, w_{t}^{G H}, w_{t}^{P H}\right)$ grow at the 
same rate as $Y_{t}$; and (iv) the private capital rental rate and private health care subsidy $\left(r_{t}\right.$, $\left.s_{t}^{H}\right)$ are constant.

The wage-growth and heath status-constancy characteristics in the BGE (instead of having it as wage being constant and health status growing like capital) are consistent with empirical evidence documented in Hartwig (2008, 2010), where health expenditure is mainly driven by wage growth over time, with limited growth-enhancing evidence from health capital formation. Next, to generate endogenous growth, given that $K_{t}^{P, i}=K_{t}^{P} \forall i$ in the symmetric equilibrium, we impose the theoretical Assumptions: $\omega(1-\varsigma)=\beta, \eta \varsigma=\epsilon$, which would then turn (18) into the standard Y-K form, with the final output-to-private capital ratio given by

$$
\frac{Y_{t}}{K_{t}^{P}}=A_{0}\left(h_{t}^{A}\right)^{\beta}
$$

and (25), after substituting in (20), to become:

$$
H_{t}^{G}=H_{0}^{G}\left(h_{t}^{A}\right)^{\eta-\epsilon}(\bar{N})^{\eta-\epsilon}\left(\Phi_{2}\right)^{\epsilon}\left(1+\frac{e_{t}^{P H}}{\nu_{H}}\right)^{\epsilon}\left(\frac{Y_{t}}{K_{t}^{P}}\right)^{\epsilon}
$$

where $\Phi_{2}=\varphi \beta v_{H} \tau \Phi_{1}, \Phi_{1}=1+\left[\tau v_{G} /\left(1-\tau v_{G}\right)\right]$.

In the Appendix, the expressions for the growth rate of private capital stock and final output are derived, with the steady-state growth rate of output along the BGE given by

$$
1+\gamma=\left(\tilde{h}^{A}\right)^{\beta} \tilde{\sigma} \beta\left[\left(1-\tilde{\xi}^{C}\right)(1-\tau-\tilde{\mu})+\tilde{\xi}^{C}(1-\tau)\right]
$$

where $\tilde{h}^{A}, \tilde{H}^{G}, \tilde{\sigma}, \tilde{\xi}^{C}$, and $\tilde{\mu}$ are the steady-state values of the respective variables.

Further, to study the transition dynamics of the model, from the Appendix, we derive a non-linear dynamic equation of the average health status, $h_{t+1}^{A}=f\left(h_{t}^{A}\right)$ :

$$
h_{t+1}^{A}=\frac{\pi_{t} \theta h_{0}\left(1+\frac{e_{t}^{P H}}{\nu_{H}}\right)^{\epsilon \nu_{C}}}{\left(\varphi \beta v_{H} \tau \Phi_{2}\right)^{-\epsilon \nu_{C}}}\left[\begin{array}{c}
\left(e_{t}^{P H}\right)^{\nu_{H}}\left(1-\xi_{t}\right) \\
+\left(e_{t}^{G H}\right)^{\nu_{H}}\left(\xi_{t}\right)^{1-\chi}
\end{array}\right]\left(h_{t}^{A}\right)^{[\eta-(1-\beta) \epsilon] \nu_{C}} .
$$


Given the complexity of the system, stability of the economy cannot be studied analytically. However, it is established numerically (based on the calibration discussed next) by solving for an initial BGE that satisfies the properties defined earlier and verifying that following a shock, or combination of shocks, the system converges to a new equilibrium in a finite number of periods.

\section{Calibration}

To examine the overall implications of dual practice on an economy, as well as the growth effects of public and private health care financing, we calibrate the model for Indonesia, a Southeast Asian developing economy whose health care financing system reform towards achieving universal coverage in the previous decade has been well-documented (Rokx et al., 2009; Fossati, 2017; González et al., 2017; Pisani et al., 2017). Further, the public availability of microdata from 5 waves of Indonesia Family Life Survey (IFLS 1-5) conducted by RAND researchers (see, for instance, Strauss et al., 2004, 2009, 2016) allows some model parameters in model equations to be empirically estimated, which we believe vastly improves reliability of findings from numerical policy experiments. In addition, macro-data from the World Health Organization (WHO)'s Global Health Observatory and World Bank's World Development Indicators databases are used. In sum, our calibration strategy focuses on matching the initial steady-state values (denoted with tilde) to the first statistical moment of relevant variables, so as to achieve a baseline that stylistically illustrates Indonesia during the period 2000-15.

First, for households, following Blackburn and Cipriani (2002), we treat adult survival rate as exogenous and set $\tilde{\pi}=0.734$, based on WHO's mortality data for the 30-70 years-old age group in $2015 .{ }^{6}$ Next, for the discount factor, $\Lambda$, we parameterize it based on Havranek

\footnotetext{
${ }^{6}$ Endogenous mortality is a topic that is well examined in the macroeconomics literature on health and growth, notably in studies such as Osang and Sakar (2008). However, it is peripheral to the core issues examined in this article. The introduction of endogenous survival rate, for instance to average health status, makes little difference to the results beyond amplifying the magnitudes of response by variables to policy
} 
et al. (2015) meta-analysis of the elasticity of intertemporal substitution for Indonesia, and yields $\Lambda=1 / 1.102=0.907$. Given this, knowing that the steady-state savings rate is given by $\tilde{\sigma}=\tilde{\pi} \Lambda /(1+\tilde{\pi} \Lambda)$, yields $\tilde{\sigma}=0.40$. This is a high value but within reasonable range of Indonesia's recent gross savings rates that are in excess of 30 percent. Further, from the Appendix, we also know that $\Lambda=(1+\gamma) /(1+\tilde{r})$ must hold in the BGE. Given that the average real GDP growth rate of Indonesia, $\gamma=0.053$ during 2000-15, this means the steadystate rental rate of physical capital, $\tilde{r}=0.161$, which is within average business lending rates in Indonesia. The relative contribution of ordinary consumption to utility, $\kappa$, is parameterized based on the relative preference parameter values for consumption and health in Agénor and Canuto (2015), which yields $\kappa=0.342$. The elasticity parameter of health status with respect to health service infrastructure, $\nu_{C}=0.55$ is set based on Osang and Sarkar (2008), while the elasticity with respect to physician efforts, $\nu_{H}$, is empirically estimated using the IFLS micro-data based on the log-linearized form of (14). ${ }^{7}$ The estimated intercept term suggests a mark-up value of approximately 13.9 times, which yields $\nu_{H}=1 / 13.9=0.072$. This suggests a benchmark of highly inelastic health response with respect to physician efforts. Given the critical role of this parameter in determining the effects of dual practice, extensive sensitivity analysis is further implemented later. For the parameter measuring the effect of illness prior to treatment, $\theta$, given that this is non-directly observable in practice, we set $\theta=0.56<\tilde{\pi}$, which is proxied by the UHC services coverage index of 56 percent for Indonesia, published by the WHO.

Next, on the physician and health system parameters, the relative preference of physician towards wage income, $\delta_{R}$, is empirically estimated based on a log-linear approximated form of the marginal condition, (17). More specifically, by exploring the cross-sectional properties shocks experimented (due to the reinforcing effect of a change in average health status). It is therefore abbreviated from this article.

${ }^{7}$ Specifically, by matching the surveyed wage data from households and the monthly revenue data from community survey of Puskemas Heads based on province and team code of the field team, we run different variations of a log-log regression of the monthly revenue (in excess of basic salary) of doctors with Private Practice on the wage income of households, controlling for factors such as community centre, province, and household IDs. 
of the responses in the IFLS, for the sample of Puskesmas Head with dual-practice, we proxy $e_{t}^{G H}$ with the (patient-adjusted) working hours per week by the Puskesmas head in the government health centre, and regress it against the ratio of the Head's total income from joint-practice (revenue plus basic salary) over his/her basic salary as Pukesmas Head, which yields an estimated coefficient of 0.095 , or equivalently, $\psi=\exp (0.097)=1.100$. This then allows us to derive $\delta_{R}=0.524$. For the private health care cost, from the WHO data in 2000-15, the average out-of-pocket and domestic private health expenditure (as percentage of health expenditure) are 49.25 and 64.27 percents respectively. Further, by dividing both outof-pocket and domestic private health expenditure per capita (PPP \$178.4 and PPP \$226) by the surveyed mean income per capita (PPP \$2,073.2) in 2015, we get 0.086 and 0.109 respectively. The former gives $\tilde{\mu}=0.086$, while the latter $\mu_{0}=0.109$. By implications, the steady-state private health care subsidy rate is $\tilde{s}^{H}=0.023$. Given the absence of comparable estimates in the literature and the relevant variable in the IFLS dataset, the (inverse) capacity congestion parameter associated with the size of patients seeking free public health care, $\chi$, is set at 0.5 for the benchmark, with its effects further examined using sensitivity analysis later.

For the production parameters, the elasticity value of Arrow-Romer externality, $\omega$, is set at 0.184, in line with meta-analysis of Bom and Ligthart (2014). The output elasticity to labor, $\beta$, is set to the national accounting-based empirical estimate for Indonesia, which gives $\beta=0.67$ (see Aswicahyono et al., 2013; Seker and Saliola, 2018). For the government, the effective tax rate, $\tau$, is calibrated as follows. Tax revenue as percentage of GDP averages at 0.114 in the period 2000-15. Given a labor income share of 0.67 , we calculate $\tau=$ $0.114 / 0.67=0.171$. On the spending shares, the share of government spending on private health subsidy can be computed by dividing the difference between domestic private and outof-pocket health expenditure by the general government expenditure, yielding an average of $v_{S}=0.022$ for the period 2000-15. By similar logic, we know the total domestic general government health expenditure as percentage of general government expenditure averages 
at 0.0526 , which is the sum of $v_{G}$ and $v_{H}$. We further calculate the value of $v_{G}$ by first, estimating the total wage bill for government doctors. Specifically, based on the physician density of 0.292 per 1000 people, we estimated the total number of physicians and then multiplied it with the sample mean-annual basic salary of Puskesmas Head reported in IFLS5. After that, we divide the estimated wage bill by the general government expenditure in current prices, yielding $v_{G}=0.004$. Given this, we then parameterize $v_{H}=0.0526-0.004=$ 0.0486. For the production of health infrastructure, the learning externality parameter, $\eta$, is parameterized using the value of Alpaslan and Ali (2018), which equals 0.3. The countryspecific government spending efficiency parameter for Indonesia is calculated based on the index values of Dabla-Norris et al. (2012), $\varphi=1.47 / 4.0=0.368$. Lastly, following Agenor et al. (2014), the elasticity of health infrastructure with respect to spending flow is set at $\epsilon=0.55$. The parameter values are summarized in Table 1 .

The remainders of the benchmark steady-state values of key variables in the BGE are determined as follows, and summarized in Table 2. First, we decide to normalize the initial steady-state value of $\tilde{H}^{G}$ and $\tilde{w}$ to 1.0 , while setting health status as an index of 100 . These are obtained by adjusting the multiplicative terms, $h_{0}, H_{0}^{G}$, and $A_{0}$. Second, based on responses in the IFLS Survey, 53.5 percent of Puskesmas Head engage in dual practice while 46.5 percent practice solely in public health services. Assuming that the responses revealed the preference of physicians in allocating their efforts, we therefore have $\tilde{e}^{G H} / \tilde{e}^{P H}=0.868$. From the survey, the average hours spent by a government doctor in Puskemas are 35.87, which given 5-working days, implies $\tilde{e}^{G H}=35.87 /\left(5^{*} 24\right)=0.299$. Given these, we calculate $\tilde{e}^{P H}=0.344$. Third, we determine the steady-state values to be set for the three wage rates. From the survey, the average basic salary of a Puskemas Head is used as a proxy for $\tilde{w}^{G H}$. The difference between this and the average reported monthly earnings allows us to then determine $\tilde{w}^{P H}$. Given the empirically estimated value for $\nu_{H}$ and the normalization of $\tilde{w}$ to unity, we know from (14) that $\tilde{w}^{P H}=13.889$, which in turn allows us to determine $\tilde{w}^{G H}=0.938$. Fourth, to determine the steady-state shares of individuals using public and 
private health care, we utilize the steady-state version of (23), and yields $1-\tilde{\xi}^{C}=0.172$. This means $\tilde{\xi}^{C}=0.828$.

\section{$5 \quad$ Policy Experiments}

To study the model properties, we first consider three individual policy experiments that are relevant to the health sector, which involve the government reallocating 0.01 share of its budget from non-productive spending to finance: (i) an increase in government spending on public physicians' wage $\left(v_{G}\right.$ increases from 0.004 to 0.014$)$; (ii) an increase in government's subsidy to private health care $\left(v_{S}\right.$ from 0.022 to 0.032$)$; and (iii) an increase in spending on broad health inrastructure $\left(v_{H}\right.$ from 0.0486 to 0.0586$)$.

To measure the permanent effects on welfare, given that our economy consists of twoperiod lived individuals, we adopt the perfect-foresight welfare criterion of overlappinggenerations models that have two-period lived agents too, such as Agénor and Lim (2018). Specifically, assume now that the economy consists of infinite number of generations of twoperiod lived individuals that will replenish by nature, the social welfare function is then given by a discounted sum of utility along the BGE path across an infinite sequence of individuals (see De la Croix and Michel, 2002, p. 91):

$$
\mathcal{W}_{t}=\sum_{h=0}^{\infty} \Psi^{h}\left[\tilde{\xi}_{0}^{C} V_{t+h}^{G H}+\left(1-\tilde{\zeta}_{0}^{C}\right) V_{t+h}^{P H}\right]
$$

where $\Psi \epsilon(0,1)$ is the social discount factor, $V_{t+h}^{G H}$ and $V_{t+h}^{P H}$ measure the indirect utility functions of individuals using public and private health services respectively, $\tilde{\xi}_{0}^{C}$ and $1-\tilde{\xi}_{0}^{C}$ are time-invariant constant weights, which we set to equal the initial steady-state shares of households using public and private health care respectively. For simplicity, we restrict the social welfare function to only measure those of the private individuals. Also for tractability, we restrict our analysis to welfare along the BGE path, with an approximation of (31) derived 
in the Appendix. All the shocks considered are permanent in nature, with the steady-state effects of key variables summarized in Table 3 and the relevant transition dynamics in Figures 1-3. In addition to the benchmark results, Table 3 also presents selected sensitivity analysis results.

\subsection{An increase in government physician wage rate}

Consider a one percentage-point permanent increase in government allocation to public physicians' wage $\left(v_{G}\right)$. In Figure 1, we see that this instantaneously increases the public-practice wage rate, therefore raises the relative wage ratio. For a given level of effort, it becomes optimal for the physician to have a higher relative ratio of (public-private) practice effort. While the relative effort ratio increases, in the margin of (17) and at the initial level of demand for private-practice effort, this means the required level of effort in public practice is lower. At the same time, from (12), an increase in the relative (public-private) effort level means an improvement in public health service quality, which leads to an increase in the share of individuals using public health care. On impact, the overall effects on average health status and therefore growth rate of final output are positive. However, in the long-run as the economy moves towards the new steady state, the fall in the demand for private health care leads to lower total revenue of the private hospital, which in turn leads to a decline in demand for the effort in private practice. A combined decrease in effort level by the physician-albeit gradually-leads to a gradual decline in the total tax income of the government. Given that government's investment in broad health infrastructure and private health subsidy is a constant fraction of the total tax income, this means lower stock of infrastructure and higher effective (out-of-pocket) household expenditure on health. These negate the initial positive effect on average health status and leads to a gradual decline in effective market wage received by average workers. This reduces the income of private individuals and consequently, consumption. In the steady state, these various general equilibrium mechanisms translate to mildly negative effect on health status $(-0.14$ percent), growth $(-0.07$ percent), and wel- 
fare $(-0.09$ percent). These suggest that, in a mixed health system where dual practice is prevalent and the private sector plays a significant role in the overall landscape, the fall-out associated with the general equilibrium effects from an increase in government physician wage rate can be negative. Indeed, this appears to be robust across most of the sensitivity analysis considered in Table 3, save for when the public sector has a very high capacity/experiences very low congestion $(\chi=5.0)$ or when the physician places low weight on her/his total earnings $\left(\delta_{R}=0.3\right)$. In the latter two cases, the opposite of a positive steady-state effect on average health status, growth, and welfare are observed. Relating these to the literature, despite a vastly different theoretical approach, the findings are in consistent with the recommendation documented in García-Prado and González (2011), where "rewarding" policies for public-sector physicians is only recommended for more developed economies (which are likely to have higher capacity in public health provision). However, the dynamic trade-off in growth (between instantaneous and steady-state effects) found is new to the literature.

\subsection{An increase in spending on private health subsidy}

Next, consider a one percentage-point permanent increase in government allocation to private health subsidy $\left(v_{S}\right)$. This can be interpreted as a stylized representation of the government increasing its support on private health care, as illustrated by Indonesia's BPJS Kesehatan system in 2014. Unlike the $v_{G}$ shock, we see in Figure 2 that the policy effects of key variables are consistent for both instantaneous and in the long-run steady state, with the transition dynamics behaving largely monotonically. On impact, an increase in $v_{S}$ raises the per-individual private health subsidy provided by the government, which from (11), reduces the total out-of-pocket health care cost of the private individuals. More individuals are then willing to pay for private health care, resulting in an increase in the share of individuals using private health service, $1-\xi_{t}^{C}$. Both the increase in the total private health expenditure and private individuals using private health service mean the private hospital responds by demanding more private practices (in terms of effort) from the physician. This increases the 
effort level supplied to private practice, at a smaller trade-off of a drop in public-practice effort level, therefore a net expansion in total physician efforts. The average health status therefore increases. In relative terms, the relative public-private effort ratio declines. The effective reduction in private health care cost borned by the individuals also translates to higher consumption and savings, the latter results in an increase in the rate of physical capital investment and consequently, final output growth. Overall in the long run, average health status in the steady state increases by 0.65 percent, final output growth by 0.55 percent, and social welfare by 0.71 percent. Intuitively, given that the model specification is such that private effort is market demand-driven, a policy that reduces effective out-ofpocket expenditure on health is necessarily growth- and welfare-enhancing. Analytically, it is more interesting to also examine the sensitivity analysis scenarios. In all the non- $\chi$ scenarios, the results are largely consistent with the benchmark results, with the welfare gains especially large when there is a larger relative contribution of goods consumption to the utility of households. The parameter $\chi$, which measures the (inverse) congestion factor of the public health service, seems to be critical in determining the structural behaviors of the model. While it is intuitive that a greater spending on private health care in a national health system with plenty of slack in its public-sector health care $(\chi=5.0)$ is growthand welfare-deteriorating ${ }^{8}$, which is along the line of arguments made in studies such as Berman and Cuizon (2004), the steady-state growth and welfare effects are negative too when public-sector health service congestion is set to a very high level $(\chi=0.1)$. These suggests a non-monotonic model response with regards to the parameter $\chi$, or the potential existence of different regimes. Further examinations are therefore implemented later in the sensitivity analysis sub-section.

\footnotetext{
${ }^{8}$ Given that an extremely large magnitude of $\chi=5.0$ is set for this specific sensitivity scenario, the large negative absolute deviations observed for growth and social welfare should therefore be interpreted with caution. Indeed, the same disclaimer should be made for other results generated, in that the absolute magnitude observed is purely in an experimental context.
} 


\subsection{An increase in spending on broad health inrastructure}

Consider a one percentage-point permanent increase in government allocation to investment in broad health infrastructure $\left(v_{H}\right)$, financed again by a reallocation from non-productive spending. As seen in Figure 3, the results observed for this policy is largely consistent with the health-promoting impact of public infrastructure investment in studies such as Agénor (2008, 2015). The reasoning is that, additional investment in broad health infrastructure benefits both public and private health care provision, therefore unambiguously raising average health status and productivity of individuals in the economy. As a result of the broad improvement in health infrastructure, a larger share of individuals can use public health service, without causing a compromising in quality. While this leads to more efforts being allocated to public practice and less to private practice, as well as a shrinking in private health care market, the net impact of a rise in relative effort ratio translates to a higher the relative wage ratio for the physician. The improvement in health outcome translates to increases in productivity and effective wage rate for ordinary workers, which in turn results in an expansion of consumption and private physical capital investment. In the steady state, this virtuous cycle of positive general equilibrium effects translates to an increase in average health status by 6.01 percent, growth by about 4.24 percent, and social welfare by 4.39 percent. This growth and welfare-enhancing outcome is largely reaffirmed by the sensitivity analysis results, including the two scenarios of $\chi$. While it can be argued that the numerical results observed appear to be overly optimistic (a standard limitation of theoretical modelbased policy analysis), in comparison to the $v_{G}$ shock, it is unambiguous that this policy is a more effective measure than a direct increase in public-sector physicians' wage in boosting growth and welfare.

\subsection{Further analysis: Financing of a mixed health system}

Having examined the three benchmark experiments, we investigate the model further by analyzing the first two measures (an increase in government physicians' wage; an increase 
in private health subsidy) for different values of $\chi$ and $\nu_{H}$. The critical role of the former is suggested in the benchmark experiments, while the latter directly influences the optimal mark-up of private practice, as seen in (14). Specifically, by focusing on the welfare effects, we repeated the two experiments across the continuous range of values for the two parameters, with results at selected intervals presented in Table 4 and 5. From the two tables, our suspicion in Section 5.1 is confirmed numerically, that the solution system would experience a structural break in a certain range of $\chi$, hence creating a two-regime solution. On one end, in the low public-sector congestion, high $\chi$ regime, the welfare effect of an increase in government physicians' wage is actually positive, though the more slack the public health care system has (larger $\chi$ ), the lower the welfare gains. On the other end, in the "normal" regime (where the benchmark case is in), the welfare effect is negative, as discussed in Section 5.1. However, the more congested the public health care system is (such as longer waiting lines, poor emergency response rates), the lower the welfare loss is associated with a pay rise for government physicians.

Similar two-regime solution is observed when the policy of an increase in private health subsidy is examined across the range of $\chi$. In the low public-sector congestion, high $\chi$ regime, the welfare effect of greater private health financing by the government is negative, though the negativity is smaller the more slack the public health care system has. In the normal regime, an increase in private health subsidy is mostly welfare-enhancing, though at extreme cases where the public sector is experiencing significant capacity issue, further support made to private health service can be welfare-deteriorating to the overall economy.

In contrast to $\chi$, the solution system appears to behave largely monotonic across different private-practice wage mark-ups, $1 / \nu_{H}$. For a "rewarding" scheme that raises government physicians' wage, with the benchmark value of $\chi=0.5$, the negative welfare effect is smaller the higher the degree of mark-up charged by the physician in private practice. In contrast, for the experiment of an increase in private health subsidy, there is actually a welfare-minimal value of $\nu_{H}=0.2488$ despite consistently positive welfare effect observed across the range of 
$\nu_{H}$. Above $\nu_{H}=0.2488$, which is a private-practice mark-up of about 4 times, the larger $\nu_{H}$ is/smaller the mark-up, the more welfare gains are made from an increase in government's subsidy in private health care.

We further investigate the financing issue by simulating the experiment of a reallocation from non-productive government spending to both private health subsidy and government physicians' wage across different combination of $\left(\chi, \nu_{H}\right)$. Numerically, this involves implementing a grid search covering the combined range of $\chi \in[0,1.5]$ and $\nu_{H} \in[0.05,0.90]$, by repeating the same experiment of an increase in $v_{G}$ from 0.004 to 0.014 and $v_{S}$ from 0.022 to 0.032 . This experiment is considered due to the reason that, in practice, national health system reform in developing countries, including Indonesia's (Rokx et al., 2009), almost always involves addressing both public and private health service. Moreover, we focus only on $\chi \in[0,1.5]$ and this "normal" regime is the likeliest characterization of the Indonesian national health system, of which low capacity/high congestion issues are well documented. In Table 6, we see that, for most parts of the grid examined, the welfare effect from such a combined reform is actually negative. This is especially true when $\nu_{H}$ is above 0.50 (privatepractice wage mark-up below 2 times of market wage), where the welfare effects across all range of $\chi \in[0,1.5]$ are negative. Nevertheless, for the benchmark combination of $(\chi=0.5$, $\left.\nu_{H}=0.072\right)$ welfare effect is positive at 0.6 percent. The welfare-optimal combination within the grid occurs when $\nu_{H}=0.05$ and $\chi=1.5$. By deduction, we therefore know that such a combined increase in mixed health financing is of the most welfare-enhancing, when privatepractice wage mark-up (over economywide average wage) is very high and the public-sector health service experiences very little congestion.

Next, Table 7 presents the results associated with an examination of a direct trade-off in health financing. Specifically, by assuming that the government faces a limitation in its ability to reallocate funds away from non-productive expenditure, it must choose between public or private health financing where an increase in one category must be financed by the other. Starting from the benchmark combination of $v_{G}=0.004$ and $v_{S}=0.022$, we examine 
this trade-off under the two different regimes of $\chi=0.5$ and $\chi=5.0$. In a normal regime (represented by the benchmark case, $\chi=0.5$ ), welfare-optimal health financing strategy appears to be promoting private health service, even if it is at the expense of public-sector physician wages. In contrast, in a low-congestion, high capacity regime $(\chi=5.0)$, a welfareoptimal strategy is to do the opposite of increasing government physician wage at the expense of private health subsidy.

The various examinations in this sub-section suggest that the question of an optimal financing of a mixed health system in developing countries does not have a straightforward answer. The different capacity or congestion issue faced by public-sector health care can result in two vastly different regimes. Further, due to the presence of a dynamic trade-off observed in Section 5.1, the policy window would matter too. These perhaps partly explain the current underperformance of Indonesia's BPJS Kesehatan system. Theoretically, while these findings are relatively new in the macroeconomics of health literature, similar tworegime results have been documented in microeconomic models such as McPake et al. (2007), which examined the flow of cross-subsidy between superior and basic service in a two-tier charging system, despite a completely different theoretical approach.

\subsection{Does initial level of spending shares matter?}

Lastly, we examine the question of whether the initial share of $v_{G}$ and $v_{G}$ influences the outcome of other health policy reform. To address this question, we study the experiment of a permanent reduction in the overall private health care cost in the economy, where $\mu_{0}$ is reduced from 0.109 to 0.0981 . For a developing economy such as Indonesia, this is often achieved through the sponsorship of medicine, equipments, and the official development assistance made by international donors. While such foreign aid flow is not incorporated into the government budget (21) due to its peripheral nature, we can examine its policy effects by assuming an exogenous decrease in $\mu_{0}$. The steady-state welfare results are presented in Table 8. Based on the different combination of public and private health spending shares, we see 
that both the growth- and welfare-optimal outcomes of this experiment are of straightforward interpretation: the larger the existing spending share of the government in both public and private health care, the more welfare gains are made when there is a decline in the timeinvariant health care cost. In other words, despite the complication observed in earlier section, both public and private health expenditure of the government have a positive level effect in facilitating other policy interventions.

\section{Concluding Remarks}

We develop an endogenous growth model with micro-foundations of a mixed health care system and physician dual-practice, to analyze the growth and welfare effects associated with different financing choice made by the government of a developing country. The model is calibrated illustratively for Indonesia, which has a well-documented mixed national health system. The main implications of this study were summarized in the introduction and need not be repeated here. We therefore conclude by pointing out that the model could be extended with more elaborative micro-structures, such as features that allows for the examination of waiting lines (Iversen, 1997), two-tier pricing strategy (McPake et al, 2007), and other health policies and regulation issues evaluated in García-Prado and González (2007). Similarly, the modeling of the preference of physician has also been vastly simplified as a selfcontained measure. For future extension, the supply of health workers in the economy can be fully endogenized to be modeled as driven by skills acquisition decision in the economy, using a framework similar to Agénor and Lim (2018).

In addition, a more systematic effort to integrate political economy considerations in assessing the performance of health system reform may also be warranted. Notably, the political consensus often needed to simultaneously meeting the needs of domestic vested interest groups versus those of foreign donors is often argued to be key to the success of mantaining and sustaining any national health system in developing countries. The implica- 
tions of these considerations on the dynamics of welfare and growth are not well-understood in the literature. On the empirical front, given the lack of country-level time series data on physician practice, pay rates, and patients' choice of health services beyond those of IFLS 1-5 means a comprehensive empirical modeling of the theoretical framework developed in this article cannot be examined. This presents an obvious future research avenue that is worth exploring. 


\section{References}

Aswicahyono, Haryo, Hill, Hal, Narjoko, Dionisius, 2013. Indonesian industrialization: A latecomer adjusting to crises. In Pathways to Industrialization in the Twenty-First Century: New Challenges and Emerging Paradigms (eds.) Szirmai, A., Naudé, W., Alcorta, L. Oxford: Oxford Scholarship.

Agénor, P, 2008. Health and infrastructure in models of endogenous growth. Journal of Macroeconomics 30 (4), 1407-1422.

Agénor, P, 2015. Public capital, health persistence and poverty traps. Journal of Economics 115 (2), 103-131.

Agénor, P., Aizenman, Joshua, 1999. Macroeconomic adjustment with segmented labor markets. Journal of Development Economics 58 (2), 277-296.

Agénor, P, Canuto, O., 2015. Gender equality and economic growth in Brazil: A long-run analysis. Journal of Macroeconomics 43 (3), 155.172.

Agénor, P, Canuto, O., Pereira da Silva, L., 2014. On gender and growth: The role of intergenerational health externalities and women's occupational constraints. Structural Change and Economic Dynamics 30 (C), 132-147.

Agénor, P, Lim, K.Y. 2018. Unemployment, growth and welfare effects of labor market reforms. Journal of Macroeconomics 58 (4), 19-38.

Agénor, P., Yilmaz, D., 2013. Aid allocation, growth and welfare with productive public goods. International Journal of Finance $\mathscr{G}$ Economics 18 (2), 103-127.

Alpaslan, B., Ali, Abdilahi, 2018. The spillover effects of innovative ideas on human capital. Review of Development Economics 22(1), 333-360.

Askildsen, Jan Erik, Holmås, Tor Helge, 2013. Wages and work conditions as determinants for physicians' work decisions. Applied Economics 45 (3), 397-406.

Berman, Peter, Cuizon, Dexter, 2004. Multiple public-private job-holding of health care providers in developing countries: an exploration of theory and evidence. Issue paper. Department for International Development Health Systems Resource Centre (DFID HSRC).

Bhattacharya, Joydeep, Qiao, Xue, 2007. Public and private expenditures on health in a growth model. Journal of Economic Dynamics and Control 31 (8), 2519-2535.

Biglaiser, Gary, Ma, Albert, 2007. Moonlighting: public service and private practice. RAND Journal of Economics 38 (4), 1113-1133.

Blackburn, Keith, Cipriani, Giam P., 2002. A model of longevity and growth. Journal of Economic Dynamics and Control 26 (2), 187-204.

Bom, Pedro, Ligthart, Jenny, 2014. What have we learned from three decades of research on the productivity of public capital? Journal of Economic Surveys 28 (5), 889-916.

Brekke, Kurt R., Sørgard, Lars, 2007. Public versus private health care in a national health service. Health Economics 16 (6), 579-601.

Chakraborty, Shankha, 2004. Endogenous lifetime and economic growth. Journal of Economic Theory 116 (1), 119-137.

Chakraborty, Shankha, Das, Mausumi, 2005. Mortality, human capital and persistent inequality. Journal of Economic Growth 10 (2), 159-192.

Dabla-Norris, Era, Brumby, Jim, Kyobe, Annette, Mills, Zac, Papageorgiou, Chris, 2012. Investing in public investment: an index of public investment efficiency. Journal of Economic Growth 17 (3), 235-266. 
De la Croix, David, Philippe, Michel, 2002. A Theory of Economic Growth: Dynamics and Policy in Overlapping Generations. Cambridge University Press.

Eggleston, Karen, Bir, Anupa, 2006. Physician dual practice. Health Policy 78, 157-166.

Ferrinho P., Van Lerberghe, W., Julien, M., Fresta, E., Gomes, A., Dias, F., Goncalves, A., Backstrom, B., 1998. How and why public sector doctors engage in private practice in Portuguese-speaking African countries. Health Policy and Planning 13 (3), 332-338.

Ferrinho, P., Van Lerberghe, W., Fronteira, I., Hipólito, F., Biscaia, A., 2004. Dual practice in the health sector: review of the evidence. Human Resources for Health 2 (1), 2-14.

Fossati, Diego, 2017. From periphery to centre: Local government and the emergence of universal healthcare in Indonesia. Contemporary Southeast Asia 39 (1), 178-203.

García-Prado, Ariadna, González, Paula, 2007. Policy and regulatory responses to dual practice in the health sector. Health Policy 84, 142-52.

García-Prado, Ariadna, González, Paula, 2011. Whom do physicians work for? An analysis of dual practice in the health sector. Journal of Health Politics, Policy and Law 36, 265-294.

González, Paula, 2004. Should physicians' dual practice be limited? An incentive approach. Health Economics 13, 505-524.

González, Paula, 2005. On a policy of transferring public patients to private practice. Health Economics 14, 513-527.

González, Paula, Macho-Stadler, Inés, 2013. A theoretical approach to dual practice regulations in the health sector. Journal of Health Economics 32 (1), 66-87.

González, Paula, Montes-Rojas, Gabriel, Pal, Sarmistha, 2017. Dual practice by health workers: Theory and evidence from Indonesia. IZA Discussion Paper Series, 11038, Bonn, Germany: IZA.

Gruen, Reinhold, Anwar, Raqibul, Begum, Tahmina, Killingsworth, James, Normand, Charles, 2002. Dual job holding practitioners in Bangladesh: an exploration. Social Science \& Medicine 54 (2), 267-279.

Hartwig, Jochen, 2008. What drives health care expenditure?-Baumol's model of 'unbalanced growth' revisited. Journal of Health Economics 27 (3), 603-623.

Hartwig, Jochen, 2010. Is health capital formation good for long-term economic growth? Panel Granger-causality evidence for OECD countries. Journal of Macroeconomics 32, 314325.

Havranek, Tomas, Horvath, Roman, Irsova, Zuzana, Rusnak, Marek, 2015. Cross-country heterogeneity in intertemporal substitution. Journal of International Economics 96 (1), 100-118.

Heshmati, Almas, 2001. On the causality between GDP and health care expenditure in augmented Solow growth model. SSE/EFI Working Paper Series in Economics and Finance 423, Stockholm School of Economics.

Hipgrave, David.B., Hort, Krishna, 2014. Dual practice by doctors working in South and East Asia: a review of its origins, scope and impact, and the options for regulation. Health Policy and Planning 29 (6), 703-716.

Humphrey, Charlotte, Russell, Jill, 2004. Motivation and values of hospital consultants in south-east England who work in the national health service and do private practice. Social Science \& Medicine 59 (6), 1241-1250.

Iversen, Tor, 1997. The effect of a private sector on the waiting time in a national health service. Journal of Health Economics 16 (4), 381-396. 
Kunze, Lars, 2014. Life expectancy and economic growth. Journal of Macroeconomics 39, 54-65.

Lagomarsino, Gina, Garabrant, Alice, Adyas, Atikah, Muga, Richard, Otoo, Nathaniel, 2012. Moving towards universal health coverage: health insurance reforms in nine developing countries in Africa and Asia. The Lancet 380 (8-14), 933-943.

Lim, K.Y., 2018. Assessing the double-edged sword of using imitation as a stepping stone to innovation: A case of Malaysia's K-economy puzzle. Singapore Economic Review. Online Ready (8 November 2017).

Madsen, J., 2018. Health-led growth since 1800. Macroeconomic Dynamics 22 (4), 961-1000.

Marchand, Maurice, Schroyen, F., 2005. Can a mixed health care system be desirable on equity grounds? Scandinavian Journal of Economics 107 (1), 1-23.

Mariani, Fabio, Pérez-Barahona, Agustín, Raffin, Natacha., 2010. Life expectancy and the environment. Journal of Economic Dynamics \& Control 34 (4), 798-815.

McPake, Barbara, Hanson, Kara, Adam, Christopher, 2007. Two-tier charging strategies in public hospitals: Implications for intra-hospital resource allocation and equity of access to hospital services. Journal of Health Economics 26, 447-462.

McPake, Barbara, Hongoro, Charles, Russo, Giuliano, 2011. Two-tier charging in Maputo Central Hospital: costs, revenues and effects on equity of access to hospital services. $B M C$ Health Services Research 11: 143.

McPake, Barbara, Russo, Giuliano, Tseng, Fu-Min, 2014. How do dual practitioners divide their time? The cases of three African capital cities. Social Science $\mathscr{E}$ Medicine 122 (December), 113-121.

Moghri, Javad, Rashidian, Arash, Arab, Mohammad, Akbari Sari, Ali, 2017. Implications of dual practice among health workers: A systematic review. Iranian Journal of Public Health 46 (2), 153-164.

Osang, Thomas, Sakar, Jayanta, 2008. Endogenous mortality, human capital and economic growth. Journal of Macroeconomics 30 (4), 1423-1445.

Pisani, Elizabeth, Kok, Maarten Olivier, Nugroho, Kharisma, 2017. Indonesia's road to universal health coverage: a political journey. Health Policy and Planning 32 (2), 267-276.

Rivera, Berta, and Currais, Luis, 2004. Public health capital and productivity in the Spanish regions: A dynamic panel data model. World Development 32 (5), 871-885.

Rokx, C., Schieber, G., Harimurti, P., Tandon, A., Somanathan, A., 2009. Health Financing in Indonesia: A Reform Road Map. Washington DC: World Bank.

Russo, Giuliano, McPake, Barbara, Fronteira, Inês, Ferrinho, Paulo, 2013. Negotiating markets for health: an exploration of physicians' engagement in dual practice in three African capital cities. Health Policy and Planning 29, 774-783.

Saksena, Priyanka, Xu, Ke, Elovainio, Riku, Perrot, J., 2010. Health services utilization and out-of-pocket expenditure at public and private facilities in low-income countries. World Health Report 2010, Background Paper, 20. World Health Organization.

Seker, Murat, Saliola, Federica, 2018. A cross-country analysis of total factor productivity using micro-level data. Central Bank Review 18, 13-27.

Socha, Karolina, Bech, Mickael, 2011. Physician dual practice: A review of literature. Health Policy 102 (1), 1-7.

Strauss, John, Beegle, Kathleen, Sikoki, Bondan, Dwiyanto, Agus, Herawati, Yulia, Witoelar, Firman, 2004. The Third Wave of the Indonesia Family Life Survey (IFLS3): Overview and 
Field Report. March. WR-144/1-NIA/NICHD.

Strauss, John, Witoelar, Firman, Sikoki, Bondan, Wattie, A.M., 2009. The Fourth Wave of the Indonesia Family Life Survey (IFLS4): Overview and Field Report. April. WR-675/1NIA/NICHD.

Strauss, John, Witoelar, Firman, Sikoki, Bondan, 2016. The Fifth Wave of the Indonesia Family Life Survey (IFLS5): Overview and Field Report. March. WR-1143/1-NIA/NICHD.

Thabrany, Hasbullah, 2008. Politics of national health insurance of Indonesia: A new era of universal coverage. In 7th European Conference on Health Economics. Rome

Wang, Kuan-Mi, 2011. Health care expenditure and economic growth: Quantile panel-type analysis. Economic Modelling 28, 1536-1549. 
Table 1

Parameter Values: Benchmark Case

\begin{tabular}{cll}
\hline \hline Parameter & \multicolumn{1}{c}{ Description } & Value \\
\hline \hline \multicolumn{2}{c}{ Households } & \\
$\Lambda$ & Discount factor & 0.907 \\
$\kappa$ & Relative contribution to utility & 0.342 \\
$\nu_{H}$ & Elasticity (health) wrt physician effort & 0.072 \\
$\nu_{C}$ & Elasticity (health) wrt infrastructure & 0.55 \\
$\theta$ & Parameter, inverse of effect of illness & 0.56 \\
Health & system and Physician & \\
$\chi$ & Congestion parameter, public health care & 0.5 \\
$\mu_{0}$ & Time-invariant private health care cost & 0.109 \\
$\delta_{R}$ & Relative physician preference, wage income & 0.524 \\
Firms & & \\
$\omega$ & Elasticity, Arrow-Romer externality & 0.184 \\
$\beta$ & Elasticity wrt effective labor & 0.67 \\
Public & sector & \\
$\tau$ & Tax rate on wages & 0.171 \\
$v_{G}$ & Share of spending on physician wage & 0.004 \\
$v_{H}$ & Share of spending on health infrastructure & 0.0486 \\
$v_{S}$ & Share of spending on private health subsidy & 0.022 \\
$\eta$ & Public infrastructure, learning externality & 0.30 \\
$\varphi$ & Parameter, spending efficiency & 0.368 \\
$\epsilon$ & Elasticity wrt spending flow, stock & 0.55 \\
\hline \hline
\end{tabular}

Table 2

Initial Steady-State Values of Key Variables

\begin{tabular}{cll}
\hline \hline Variable & \multicolumn{1}{c}{ Description } & Value \\
\hline \hline$\tilde{\xi}^{C}$ & Share of individuals using public health care & 0.828 \\
$\tilde{e}^{P H}$ & Effort allocated to private practice, physician & 0.344 \\
$\tilde{e}^{G H}$ & Effort allocated to public practice, physician & 0.299 \\
$\tilde{h}^{A}$ & Average adult health status & 100.0 \\
$\tilde{H}^{G}$ & Stock of health infrastructure & 1.000 \\
$\tilde{\mu}$ & Private health care cost, fraction of market wage & 0.086 \\
$\tilde{s}^{H}$ & Private health care subsidy rate & 0.023 \\
$\tilde{w}$ & Market wage rate & 1.000 \\
$\tilde{w}^{P H}$ & Physician wage rate, private practice & 13.889 \\
$\tilde{w}^{G H}$ & Physician wage rate, public practice & 0.938 \\
$\tilde{\pi}$ & Adult survival probability & 0.734 \\
$\gamma$ & Final output growth rate & 0.053 \\
\hline \hline
\end{tabular}


Table 3

Results Summary for Policy Experiments: Steady-state effects

(Percentage deviations for health status and social welfare; Absolute deviations from baseline for all others) An increase in government spending on public physicians' wage $\left(v_{G}\right)$

\begin{tabular}{|c|c|c|c|c|c|c|c|c|}
\hline & Initial Values & Benchmark & $x=0.1$ & $x=5.0$ & $v_{H}=0.7$ & $v_{c}=0.1$ & $\mathrm{k}=0.8$ & $\delta_{R}=0.3$ \\
\hline Share of public patients & 0.828 & 0.0003 & 0.0003 & -0.0004 & 0.0002 & 0.0004 & 0.0003 & -0.0035 \\
\hline Relative effort ratio (public/private) & 0.868 & 0.0026 & 0.0008 & -0.0279 & 0.0002 & 0.0032 & 0.0033 & -0.0271 \\
\hline Physician's effort level in public practice & 0.299 & -0.0008 & -0.0012 & -0.0073 & -0.0058 & -0.0007 & -0.0007 & 0.0114 \\
\hline Physician's effort level in private practice & 0.344 & -0.0020 & -0.0017 & 0.0027 & -0.0067 & -0.0021 & -0.0021 & 0.0246 \\
\hline Ratio of public-practice wage rate to private-practice wage rate & 0.068 & 0.1696 & 0.1699 & 0.1760 & 1.5853 & 0.1696 & 0.1694 & 0.1666 \\
\hline Public-practice wage rate & 0.938 & 2.3564 & 2.3613 & 2.4410 & 2.2817 & 2.3565 & 2.3546 & 2.2885 \\
\hline Private-practice wage rate & 13.889 & 0.0063 & 0.0051 & -0.0137 & 0.0077 & 0.0026 & 0.0065 & -0.1095 \\
\hline Health status* & 100.0 & -0.0014 & -0.0011 & 0.0030 & -0.0161 & -0.0006 & -0.0014 & 0.0243 \\
\hline Growth rate & 0.053 & -0.0009 & -0.0007 & 0.0021 & -0.0113 & -0.0003 & -0.0010 & 0.0166 \\
\hline Social welfare* & 41.0 & -0.0012 & -0.0010 & 0.0023 & -0.0182 & -0.0005 & -0.0346 & 0.0210 \\
\hline \multicolumn{9}{|c|}{ An increase in government spending on private health subsidy $\left(U_{S}\right)$} \\
\hline & Initial Values & Benchmark & $x=0.1$ & $x=5.0$ & $v_{H}=0.7$ & $v_{c}=0.1$ & $\mathrm{~K}=0.8$ & $\delta_{R}=0.3$ \\
\hline Share of public patients & 0.828 & -0.0099 & -0.0086 & 0.0135 & -0.0090 & -0.0102 & -0.0081 & -0.0102 \\
\hline Relative effort ratio (public/private) & 0.868 & -0.0249 & 0.0369 & 2.0196 & -0.0018 & -0.0270 & 0.0571 & -0.0266 \\
\hline Physician's effort level in public practice & 0.299 & -0.0053 & 0.0078 & 0.3131 & -0.0004 & -0.0058 & 0.0120 & -0.0047 \\
\hline Physician's effort level in private practice & 0.344 & 0.0038 & -0.0054 & -0.1325 & 0.0003 & 0.0042 & -0.0083 & 0.0054 \\
\hline Ratio of public-practice wage rate to private-practice wage rate & 0.068 & 0.0017 & -0.0019 & -0.0394 & 0.0035 & 0.0016 & -0.0027 & 0.0016 \\
\hline Public-practice wage rate & 0.938 & 0.0214 & -0.0257 & -0.5280 & 0.0037 & 0.0214 & -0.0375 & 0.0203 \\
\hline Private-practice wage rate & 13.889 & -0.0296 & 0.0092 & 0.6846 & -0.0020 & -0.0178 & 0.0029 & -0.0364 \\
\hline Health status* & 100.0 & 0.0065 & -0.0020 & -0.1357 & 0.0043 & 0.0039 & -0.0006 & 0.0080 \\
\hline Growth rate & 0.053 & 0.0055 & -0.0003 & -0.0943 & 0.0040 & 0.0036 & 0.0007 & 0.0065 \\
\hline Social welfare* & 41.0 & 0.0071 & -0.0005 & -0.1102 & 0.0063 & 0.0048 & 0.0452 & 0.0084 \\
\hline \multicolumn{9}{|c|}{ A increase in government spending on broad health inrastructure $\left(v_{H}\right)$} \\
\hline & Initial Values & Benchmark & $x=0.1$ & $x=5.0$ & $v_{H}=0.7$ & $v_{C}=0.1$ & $\mathrm{~K}=0.8$ & $\delta_{R}=0.3$ \\
\hline Share of public patients & 0.828 & 0.0030 & 0.0026 & -0.0043 & 0.0024 & 0.0005 & 0.0031 & 0.0031 \\
\hline Relative effort ratio (public/private) & 0.868 & 0.0244 & 0.0055 & -0.2632 & 0.0020 & 0.0043 & 0.0277 & 0.0249 \\
\hline Physician's effort level in public practice & 0.299 & 0.0051 & 0.0011 & -0.0607 & 0.0002 & 0.0009 & 0.0058 & 0.0049 \\
\hline Physician's effort level in private practice & 0.344 & -0.0037 & -0.0009 & 0.0496 & -0.0005 & -0.0007 & -0.0042 & -0.0041 \\
\hline Ratio of public-practice wage rate to private-practice wage rate & 0.068 & 0.0026 & 0.0038 & 0.0267 & 0.0386 & 0.0005 & 0.0025 & 0.0027 \\
\hline Public-practice wage rate & 0.938 & 0.0181 & 0.0327 & 0.3265 & 0.0363 & 0.0032 & 0.0157 & 0.0184 \\
\hline Private-practice wage rate & 13.889 & -0.2651 & -0.2766 & -0.4738 & -0.0282 & -0.0478 & -0.2639 & -0.2631 \\
\hline Health status* & 100.0 & 0.0601 & 0.0628 & 0.1109 & 0.0623 & 0.0105 & 0.0598 & 0.0597 \\
\hline Growth rate & 0.053 & 0.0424 & 0.0443 & 0.0762 & 0.0439 & 0.0075 & 0.0423 & 0.0421 \\
\hline Social welfare* & 41.0 & 0.0439 & 0.0469 & 0.0735 & 0.0580 & 0.0078 & 1.4564 & 0.0435 \\
\hline
\end{tabular}

Note: Both health status and social welfare are in index, and therefore is calculated as percentage deviation from initial baseline value

All 3 experiments involve the government making an additional 0.01 share of its expenditure to the specific category, by reducing non-productive expenditure. Source: Authors' calculations. 
Table 4: An increase in government physicians' wage, for different value of $\chi$ and $\boldsymbol{v}_{\mathrm{H}}{ }^{*}$

Percentage deviation from the initial baseline level of social welfare

\begin{tabular}{r|l}
$\mathbf{0 . 1}$ & -0.0010 \\
$\mathbf{0 . 5}$ & -0.0012 \\
$\mathbf{1 . 0}$ & -0.0016 \\
$\mathbf{1 . 5}$ & -0.0022 \\
$\mathbf{2 . 0}$ & -0.0033 \\
$\mathbf{2 . 5}$ & -0.0067 \\
$\mathbf{2 . 7 8 5}$ & -0.0106
\end{tabular}

Structural break**

\begin{tabular}{r|l}
3.127 & 0.0820 \\
3.2 & 0.0273 \\
3.5 & 0.0090 \\
4.0 & 0.0044 \\
4.5 & 0.0030 \\
5.0 & 0.0023
\end{tabular}

\begin{tabular}{c|c}
$\boldsymbol{v}_{H}$ & \\
$\mathbf{0 . 1 0}$ & -0.0016 \\
$\mathbf{0 . 2 0}$ & -0.0033 \\
$\mathbf{0 . 3 0}$ & -0.0053 \\
$\mathbf{0 . 4 0}$ & -0.0079 \\
$\mathbf{0 . 5 0}$ & -0.0108 \\
$\mathbf{0 . 6 0}$ & -0.0143 \\
$\mathbf{0 . 7 0}$ & -0.0182 \\
$\mathbf{0 . 8 0}$ & -0.0227 \\
$\mathbf{0 . 9 0}$ & -0.0277 \\
$\mathbf{1 . 0 0}$ & -0.0340 \\
$\mathbf{1 . 1 0}$ & -0.0398 \\
$\mathbf{1 . 2 0}$ & -0.0469 \\
$\mathbf{1 . 3 0}$ & -0.0550 \\
$\mathbf{1 . 4 0}$ & -0.0641 \\
$\mathbf{1 . 5 0}$ & -0.0745
\end{tabular}

* This involves an increase in $v_{\mathrm{G}}$ from 0.004 to 0.014 .

** Model is not solvable between the range of $\chi=2.786-3.126$.

Table 5: An increase in private health subsidy, for different value of $\chi$ and $v_{\mathrm{H}}{ }^{*}$

Percentage deviation from the initial baseline level of social welfare

\begin{tabular}{r|r} 
& \multicolumn{1}{|l}{$\chi$} \\
$\mathbf{0 . 1}$ & -0.0005 \\
$\mathbf{0 . 5}$ & 0.0071 \\
$\mathbf{1 . 0}$ & 0.0203 \\
$\mathbf{1 . 5}$ & 0.0414 \\
$\mathbf{2 . 0}$ & 0.0803 \\
$\mathbf{2 . 5}$ & 0.1565 \\
$\mathbf{2 . 7 8 2}$ & 0.2040
\end{tabular}

Structural break**

\begin{tabular}{r|r|r|r}
$\mathbf{3 . 9 0 4}$ & -0.2806 & $\mathbf{1 . 0 0}$ & 0.0075 \\
$\mathbf{4 . 0}$ & -0.2206 & $\mathbf{1 . 1 0}$ & 0.0079 \\
$\mathbf{4 . 5}$ & -0.1390 & $\mathbf{1 . 2 0}$ & 0.0084 \\
$\mathbf{5 . 0}$ & -0.1102 & $\mathbf{1 . 3 0}$ & 0.0090 \\
& & $\mathbf{1 . 4 0}$ & 0.0097 \\
& & $\mathbf{1 . 5 0}$ & 0.0104
\end{tabular}

* This involves an increase in $v_{\mathrm{S}}$ from 0.022 to 0.032 .

** Model system not solvable between the range of $\chi=2.783-3.903$. 
Table 6: A reallocation in government spending share from non-productive spending to both private health subsidy \& government physicians'

wage*

Percentage deviation from the initial baseline level of social welfare

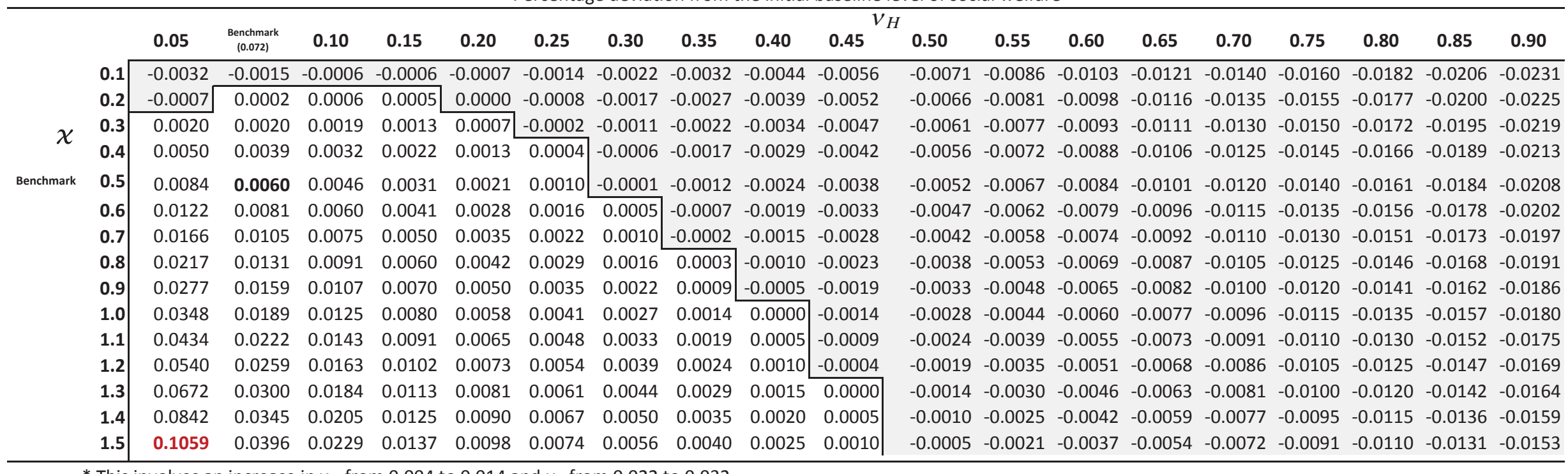

$*$ This involves an increase in $v_{\mathrm{G}}$ from 0.004 to 0.014 and $v_{\mathrm{S}}$ from 0.022 to 0.032 . 
Table 7

Trade-offs between a change in government physicians' wage versus a change in private health subsidy, for different congestion parameters

Percentage deviation from the initial baseline level of social welfare

\begin{tabular}{|c|c|c|c|c|c|c|c|c|c|c|}
\hline & & $\chi=0.5$ & & & & $v_{G}$ & & & & \\
\hline & & -0.003 & -0.002 & -0.001 & 0.000 & +0.001 & +0.002 & +0.003 & +0.004 & +0.005 \\
\hline & -0.003 & -0.00144 & -0.00162 & -0.00178 & -0.00193 & -0.00207 & -0.00221 & -0.00234 & -0.00246 & -0.00258 \\
\hline & -0.002 & -0.00080 & -0.00098 & -0.00115 & -0.00130 & -0.00144 & -0.00158 & -0.00170 & -0.00183 & -0.00194 \\
\hline & -0.001 & -0.00016 & -0.00034 & -0.00050 & -0.00065 & -0.00080 & -0.00093 & -0.00106 & -0.00118 & -0.00130 \\
\hline y & 0.000 & 0.00049 & 0.00031 & 0.00015 & 0.00000 & -0.00014 & -0.00028 & -0.00040 & -0.00053 & -0.00064 \\
\hline & +0.001 & 0.00116 & 0.00098 & 0.00082 & 0.00066 & 0.00052 & 0.00039 & 0.00026 & 0.00014 & 0.00002 \\
\hline & +0.002 & 0.00183 & 0.00165 & 0.00149 & 0.00134 & 0.00120 & 0.00106 & 0.00094 & 0.00081 & 0.00070 \\
\hline & +0.003 & 0.00252 & 0.00234 & 0.00218 & 0.00203 & 0.00188 & 0.00175 & 0.00162 & 0.00150 & 0.00138 \\
\hline & & $\chi=5.0$ & & & & $v_{G}$ & & & & \\
\hline & & -0.003 & -0.002 & -0.001 & 0.000 & +0 & +0 & 03 & 04 & +0.005 \\
\hline & -0.003 & 0.02945 & 0.02974 & 0.03001 & 0.03027 & 0.03052 & 0.03076 & 0.03100 & 0.03123 & 0.03146 \\
\hline & -0.002 & 0.01942 & 0.01971 & 0.01999 & 0.02025 & 0.02050 & 0.02074 & 0.02098 & 0.02122 & 0.02144 \\
\hline & -0.001 & 0.00933 & 0.00962 & 0.00990 & 0.01016 & 0.01042 & 0.01067 & 0.01091 & 0.01114 & 0.01137 \\
\hline & 0.000 & -0.00085 & -0.00055 & -0.00027 & 0.00000 & 0.00026 & 0.00051 & 0.00075 & 0.00099 & 0.00122 \\
\hline & +0.001 & -0.01112 & -0.01082 & -0.01053 & -0.01026 & -0.01000 & -0.00975 & -0.00950 & -0.00927 & -0.00903 \\
\hline & +0.002 & -0.02152 & -0.02121 & -0.02092 & -0.02064 & -0.02038 & -0.02012 & -0.01987 & -0.01963 & -0.01940 \\
\hline & +0.003 & -0.03205 & -0.03173 & -0.03143 & -0.03115 & -0.03089 & -0.03063 & -0.03037 & -0.03013 & -0.02989 \\
\hline
\end{tabular}

Table 8

A permanent reduction in the overall private health care cost, $\mu_{0}$, by 10 percent* Percentage deviation from the initial baseline level of social welfare

\begin{tabular}{rr|rrrrrr} 
& & \multicolumn{6}{c}{$v_{G}$} \\
$v_{S} v_{S}$ & $\mathbf{0 . 0 1}$ & 0.00132 & 0.00132 & 0.00132 & 0.00132 & 0.00132 & 0.00132 \\
& $\mathbf{0 . 0 2}$ & 0.00669 & 0.00671 & 0.00674 & 0.00676 & 0.00678 & 0.00681 \\
& $\mathbf{0 . 0 3}$ & 0.01423 & 0.01430 & 0.01437 & 0.01443 & 0.01450 & 0.01456 \\
& $\mathbf{0 . 0 4}$ & 0.02633 & 0.02651 & 0.02667 & 0.02683 & 0.02699 & 0.02714 \\
& $\mathbf{0 . 0 5}$ & 0.05097 & 0.05150 & 0.05200 & 0.05248 & 0.05294 & 0.05340 \\
& $\mathbf{0 . 0 6}$ & 0.14294 & 0.14587 & 0.14866 & 0.15137 & 0.15403 & $\mathbf{0 . 1 5 6 6 4}$
\end{tabular}

Absolute deviation from the baseline steady-state growth rate

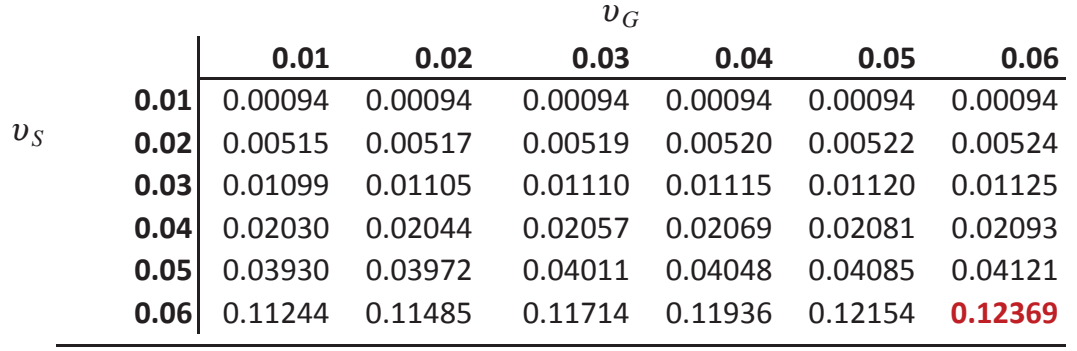

* This involves a reduction in $\mu_{0}$ from 0.109 to 0.0981 . 


\section{Figure 1}

A permanent increase in government physician wage rate

An increase in $v_{G}$ from 0.004 to 0.014

(Percentage deviation for health status; Absolute deviations for others)

$$
\text { - Benchmark } \quad-\chi=0.1--\kappa=0.8
$$
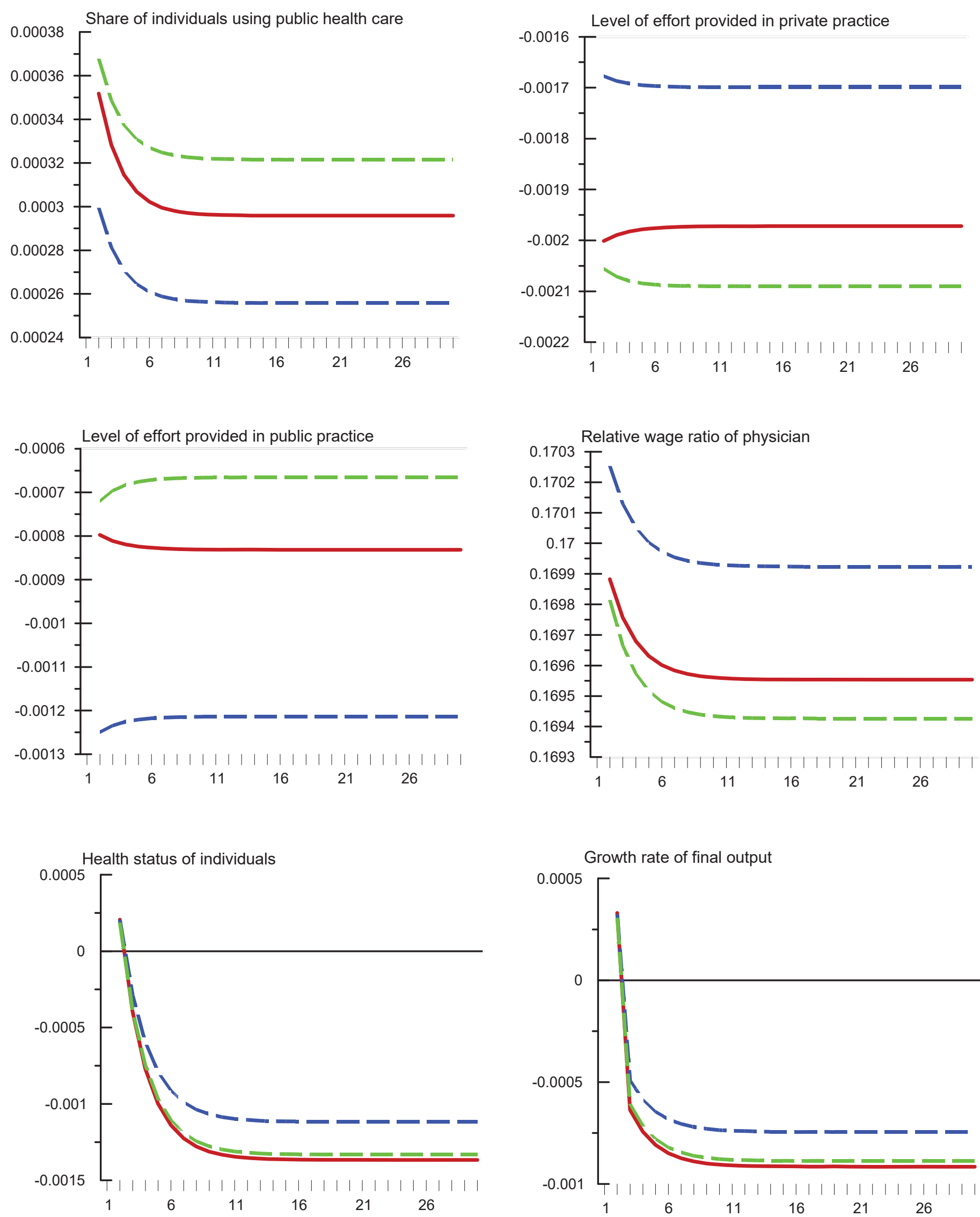
Figure 2

A permanent increase in government spending on private health subsidy

An increase in $v_{S}$ from 0.022 to 0.032

(Percentage deviation for health status; Absolute deviations for others)

$$
\text { - Benchmark } \quad-\chi=0.1 \quad-\delta_{R}=0.3
$$
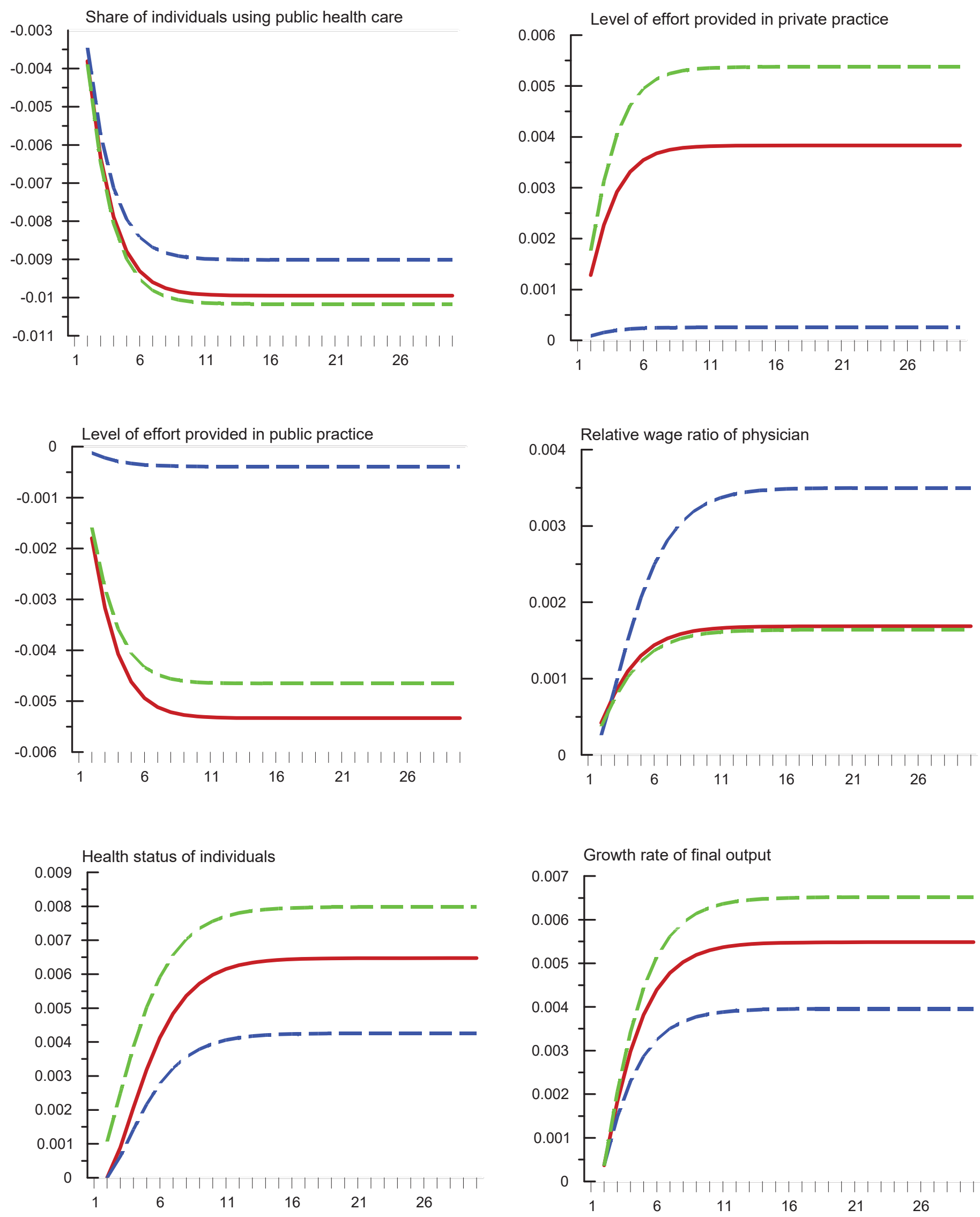
Figure 3

A permanent increase in spending on broad health infrastructure

An increase in $v_{H}$ from 0.0486 to 0.0586

(Percentage deviation for health status; Absolute deviations for others)

- Benchmark $\quad-\eta=0.5 \quad-v_{C}=0.7$
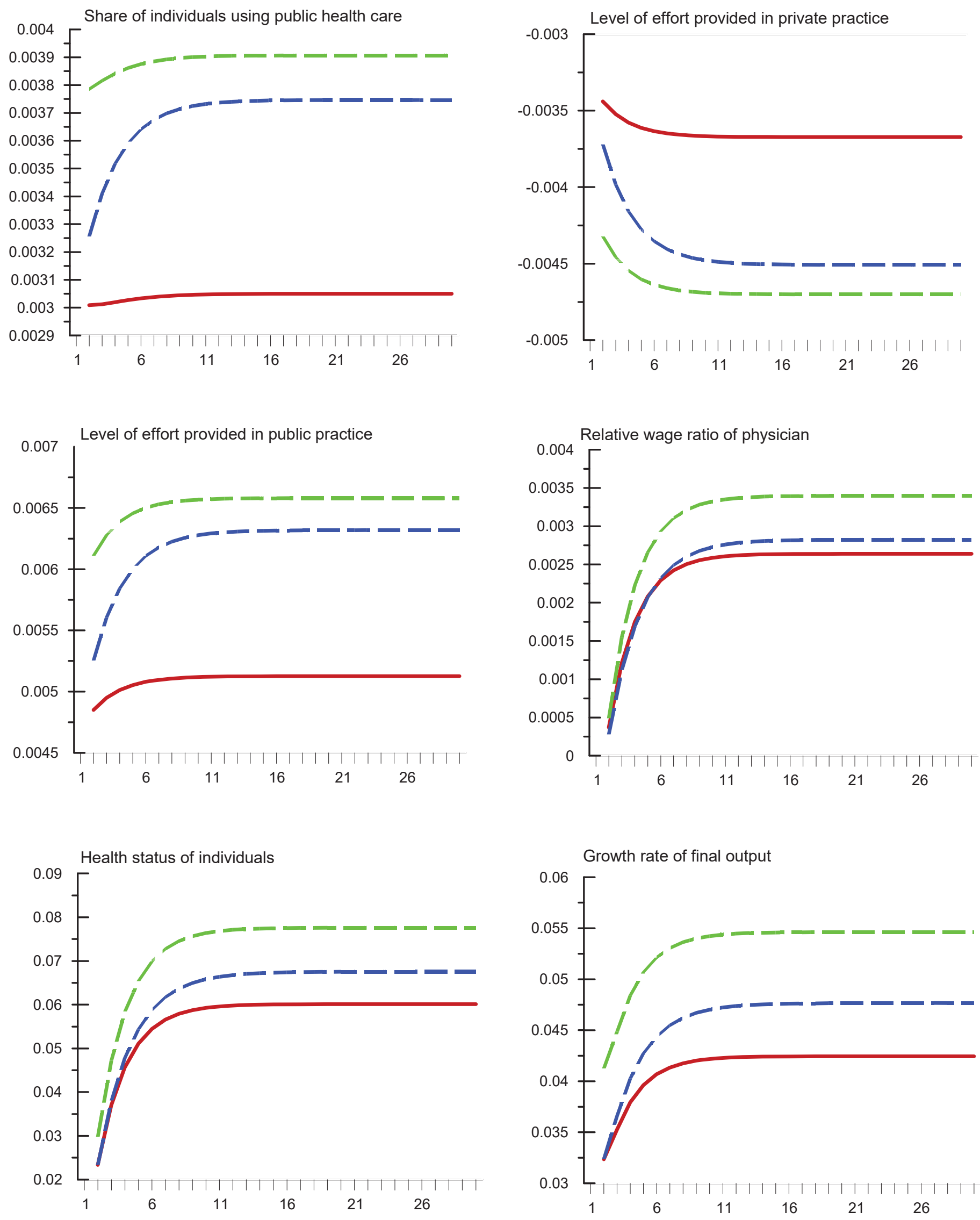